\title{
REPORT ON THE PLANNING WORKSHOP ON COST-EFFECTIVE CERAMIC MACHINING
}

May 22-23, 1991

\author{
P. J. Blau \\ Metals and Ceramics Division \\ Oak Ridge National Laboratory \\ P. O. Box 2008 \\ Oak Ridge, TN 37831-6063
}

for

Office of Transportation Materials Office $\mathrm{c}^{f}$ Transportation Technologies Conservation and Renewable Energy

U. S. Department of Energy

November 1991

\section{OAK RIDGE NATIONAL LABORATORY \\ Managed by \\ Martin-Marietta Energy Systems, Inc. \\ under contract DE-AC05-84OR21400}

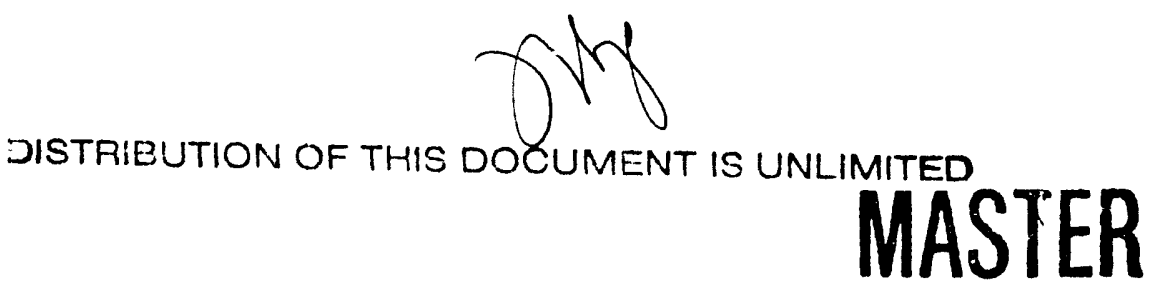




\section{CONTENTS}

EXECUTIVE SUMMARY $\ldots \ldots \ldots \ldots \ldots \ldots \ldots \ldots \ldots \ldots \ldots \ldots \ldots \ldots \ldots$ iv

1.0 BACKGROUND $\ldots \ldots \ldots \ldots \ldots \ldots \ldots \ldots \ldots \ldots \ldots \ldots \ldots \ldots \ldots \ldots$

$2.0 \quad$ HIGHLIGHTS OF INVITED PRESENTATIONS $\ldots \ldots \ldots \ldots \ldots \ldots$

3.0 THE PROPOSED CECM PROJECT PLAN $\ldots \ldots \ldots \ldots \ldots \ldots \ldots \ldots$

4.0 SURVEY DESCRIPTION AND RESULTS $\ldots \ldots \ldots \ldots \ldots \ldots \ldots$

5.0 SUMMARY AND REVISED CECM PLAN $\ldots \ldots \ldots \ldots \ldots \ldots \ldots \ldots \ldots \ldots$

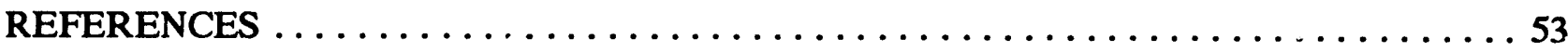

APPENDICES:

A. LIST OF ON-SITE WORKSHOP REGISTRANTS $\ldots \ldots \ldots \ldots \ldots \ldots$

B. SPECIFIC COMMENTS FROM THE WORKSHOP

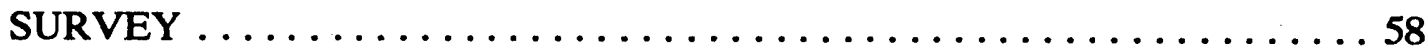




\section{SUMMARY}

A workshop on "Cost Effective Ceramic Machining" (CECM) was held at Oak Ridge Associated Universities Pollard Auditorium, Oak Ridge, Tennessee, on Wednesday, May 22, and Thursday, May 23, 1991. The purpose of this workshop was to present a preliminary project plan for industry critique and to identify specific components and cost-reduction targets for a new project on Cost Effective Ceramic Machining. The CECM project is an extension of the work on the Ceramic Technology for Advanced Heat Engines (CTAHE) Program sponsored by the Department of Energy, Office of Transportation Materials. The workshop consisted of fifteen invited papers, discussions, a survey of the attendee's opinions, and a tour of the High Temperature Materials Laboratory at ORNL. The total number of registrants was sixty-seven, including thirty-three from industry or private sector organizations, seven from universities, three from industry groups, fourteen from DOE laboratories (including ORNL, Y-12, and Lawrence Livermore Laboratory), three from trade associations, and three from other government organizations.

Forty-one survey forms, which critiqued the proposed project plan, were completed by attendees, and the results are presented in this report. Valves, cam roller followers, water pump seals, and diesel engine head plates were rated highest for application of ceramic machining concepts to reduce cost. Coarse grinding, abrasives and wheel technology, and fine grinding were most highly rated as regards their impact on cost reduction. Specific cost-reduction targets for given parts varied greatly in the survey results and were not felt to be useful for the purposes of the CECM plan development. A range of individual comments were obtained and are listed in an appendix.

As a result of the workshop and subsequent discussions, a modified project plan, different in certain aspects from the original CECM plan, has been developed.

Research sponsored by the U.S. Department of Energy, Assistant Secretary for Conservation and Renewable Energy, Office of Transportation Materials, Tribology Program, under contract DE-AC05-84OR21400 with Martin Marietta Energy Systems, Inc. 


\subsection{BACKGROUND}

In response to a request by the U.S. Department of Energy, Office of Vehicle R\&D (now the Office of Transportation Materials), Oak Ridge National Laboratory staff developed a program on "Ceramic Technology for Advanced Heat Engines (CTAHE)" and published the program plan in 1984 [1]. The program goal was stated as follows:

".to develop an industrial technology base capable of providing reliable and cost-effective structural ceramics for use in advanced heat engines."

A number of overviews and surveys, coupled with direct interaction with industry, resulted in the development of a major effort which concentrated on improving the properties and processing of structural ceramics. This effort continues to the present time under the auspices of the DOE, Office of Transportation Technologies. Many of the initial ceramic property goals have been achieved or will be met within the next few years. However, a major new thrust, which emphasizes cost reduction issues, has been identified as necessary for near-term commercialization and is scheduled for implementation beginning in FY 1992. The most recent version of the program plan reflected the increased emphasis on cost reduction [2]. A portion of this low-cost ceramics initiative deals with the high-cost of machining ceramics.

Figure 1 is a projection of the ceramics markets for the year 2000 [3]. Heat engine materials represent a significant fraction of the projected ceramics utilization; however, if markets for U.S. structural ceramics are too develop, work on cost reduction must begin at once. Figure 2 is data from Norton Company [4] which indicates how strongly the overall cost of parts can be influenced by machining costs.

A "Cost-Effective Ceramic Machining (CECM)" effort is in the planning stage. Its goals and objectives are:

"to develop, with the participation of U. S. industry, advanced, cost-effective ceramic machining methods and strategies; especially, as related to the introduction of ceramics into energy-efficient, low-emissions transportation systems."

In a manner consistent with the Ceramic Technology program, an attempt is being made to develop a project plan based on discussions with a wide range of industry, government, and university input. Part of the CECM plan involved holding a planning workshop to which a variety of individuals were invited. The workshop was held on May 22-23, 1991, in Oak Ridge, Tennessee, and consisted of invited talks, a poster session, and the presentation of a proposed CECM project plan in conjunction with a written survey of the workshop attendees. This report summarizes the workshop, the proposed plan, and the results of the survey. It is intended to help establish the goals for the CECM project for the next five years.

The composition of the sixty-seven workshop registrants is shown in Fig. 3. It was hoped that industry would make a strong showing at the workshop, and they did represent over $58 \%$ of those in attendance. University faculty made up $13 \%$ of the attendees. The diversity of individual backgrounds and viewpoints promoted several lively discussions during the course of the workshop.

\section{HIGHLIGHTS OF PRESENTATIONS}

The CECM workshop program is shown in Fig. 4. This section presents condensed highlights 


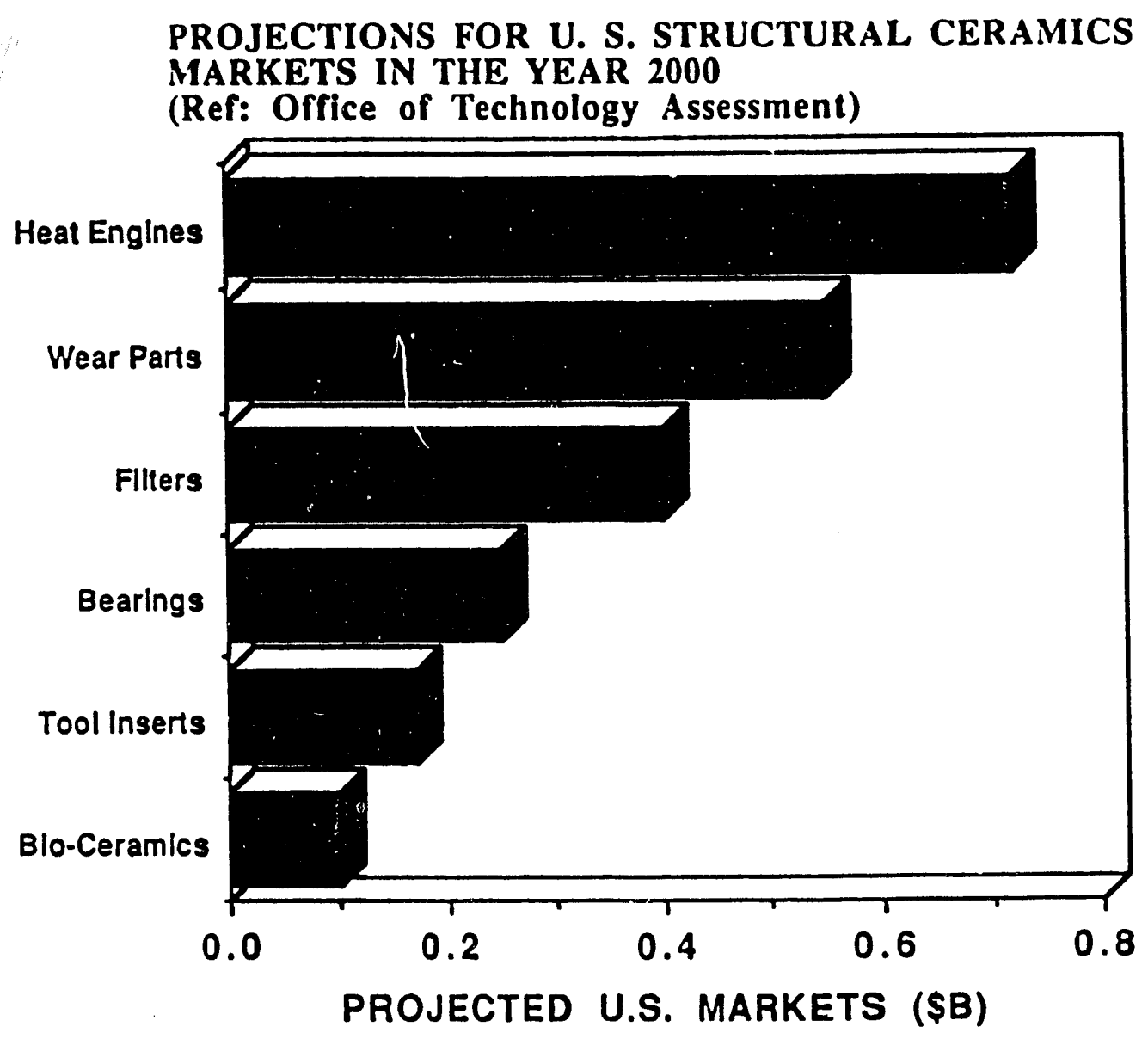

Figure 1. Market projections for ceramic parts in the year 2000. 


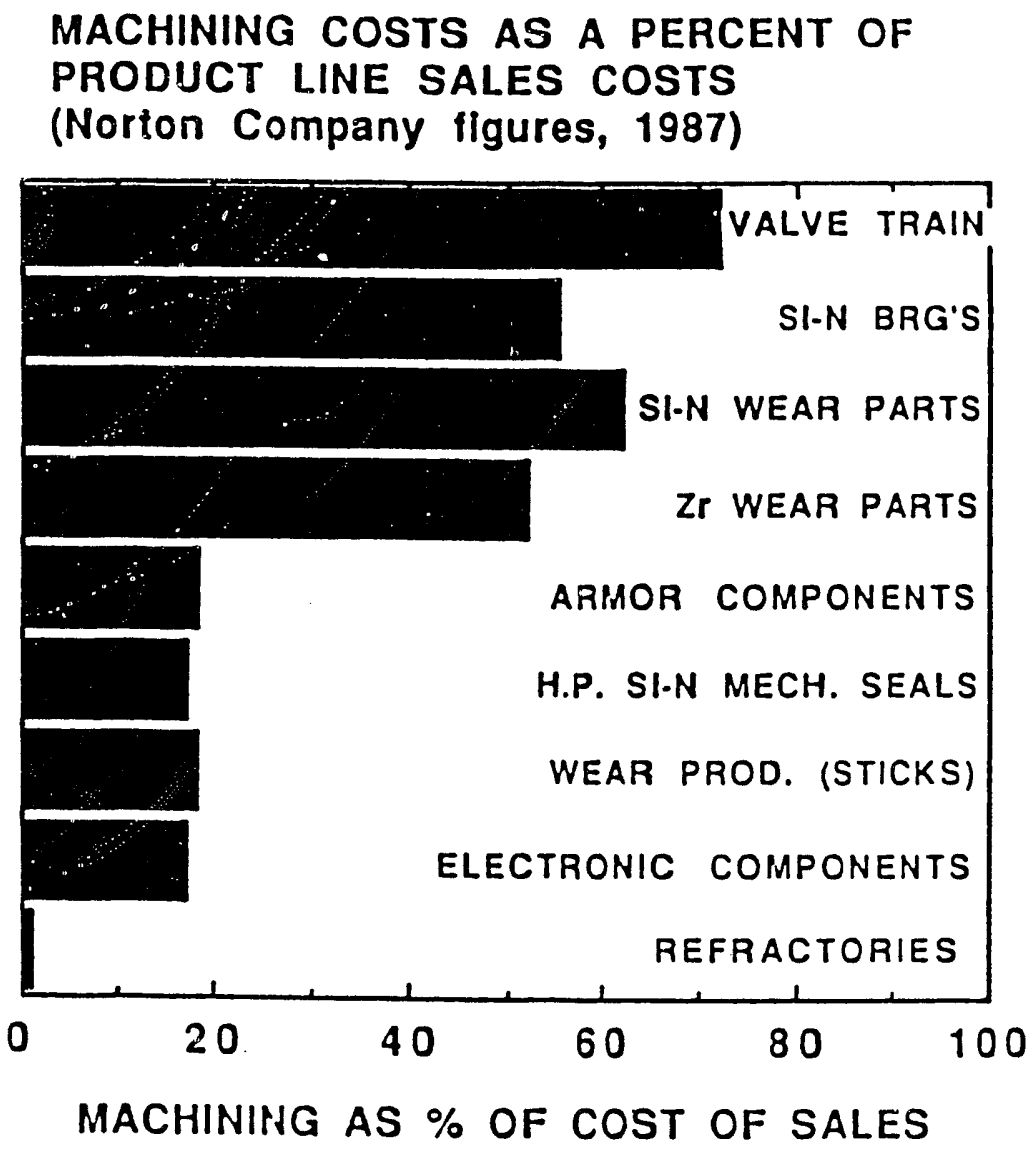

Figure 2. Typical machining costs as a percentage of total cost for selected parts categories (Norton Company data). 


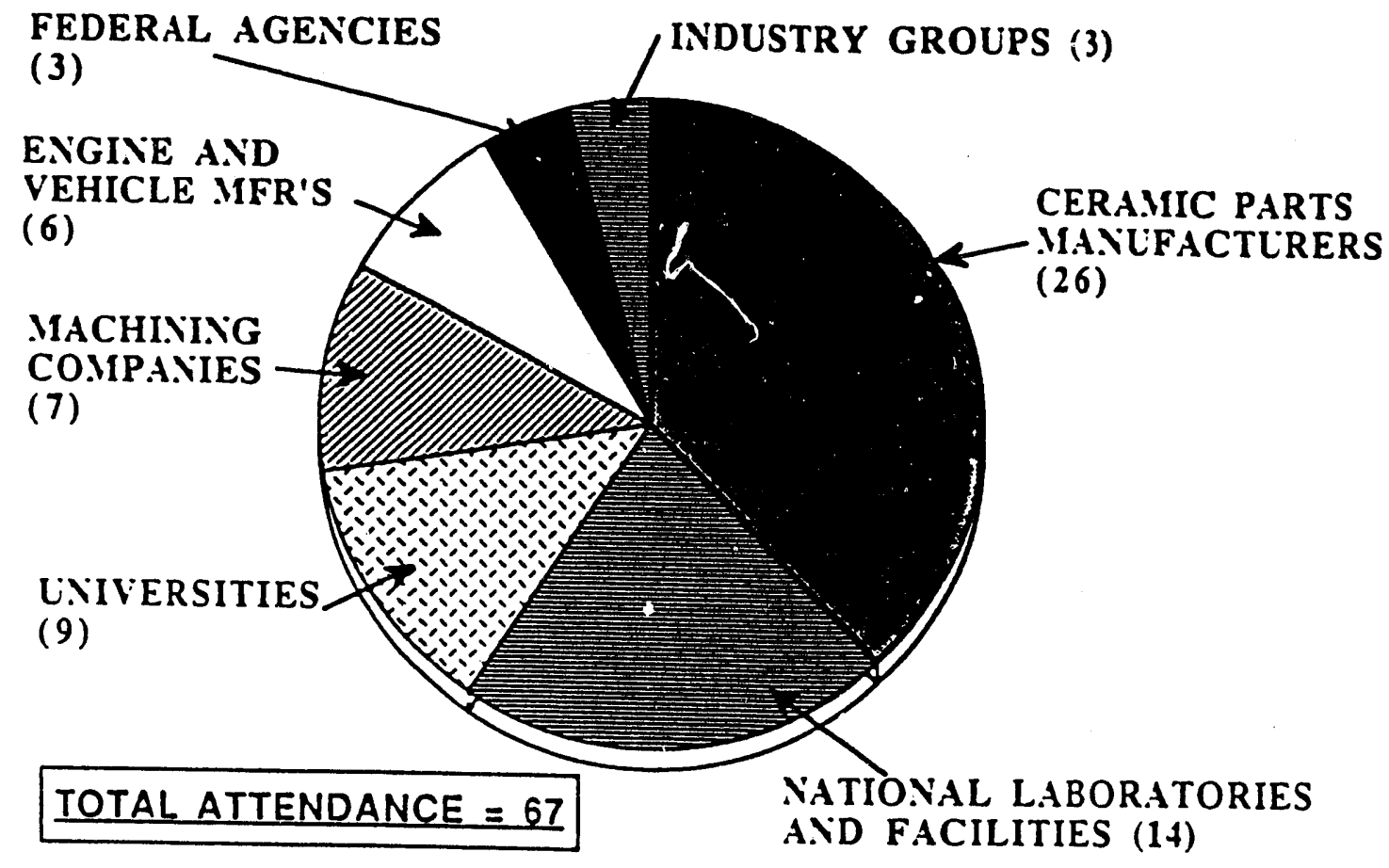

Figure 3. Break-down of workshop attendee affiliations. 


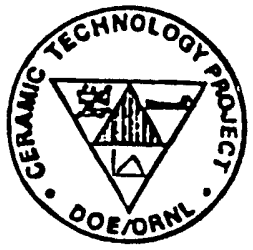

U.S. Department of Energy Offlce of Transportation Technologles

and

Oak RIdge National Laboratory

COST-EFFECTIVE CERAMIC MACHINING (CECM): Project Planning Workshop

May 22-23, 1991

Pollard Auditorium Oak Ridge, Tennessee

\section{Purpose}

The purpose of this workshop is to provide information and guidance for developing a multi-year research and development plas aimed at reducing the costs of machining ceramic pars for use in energy-efricient and altemative.fueled car and truck engines, and enhancing U. S. compecitiveness in the intermational ceramics industry. Perspectives will be given by nipresentatives of the transporation industry, ceramics comparies, and organizations that specialize in machining. In addition, there will be presentations of related government programs. Bolb formal sessions and informal poster/display sessions will provide the opportunity for productive information interchange.

Wednesday. May 22:

\section{《 PROGRAM $\gg$}

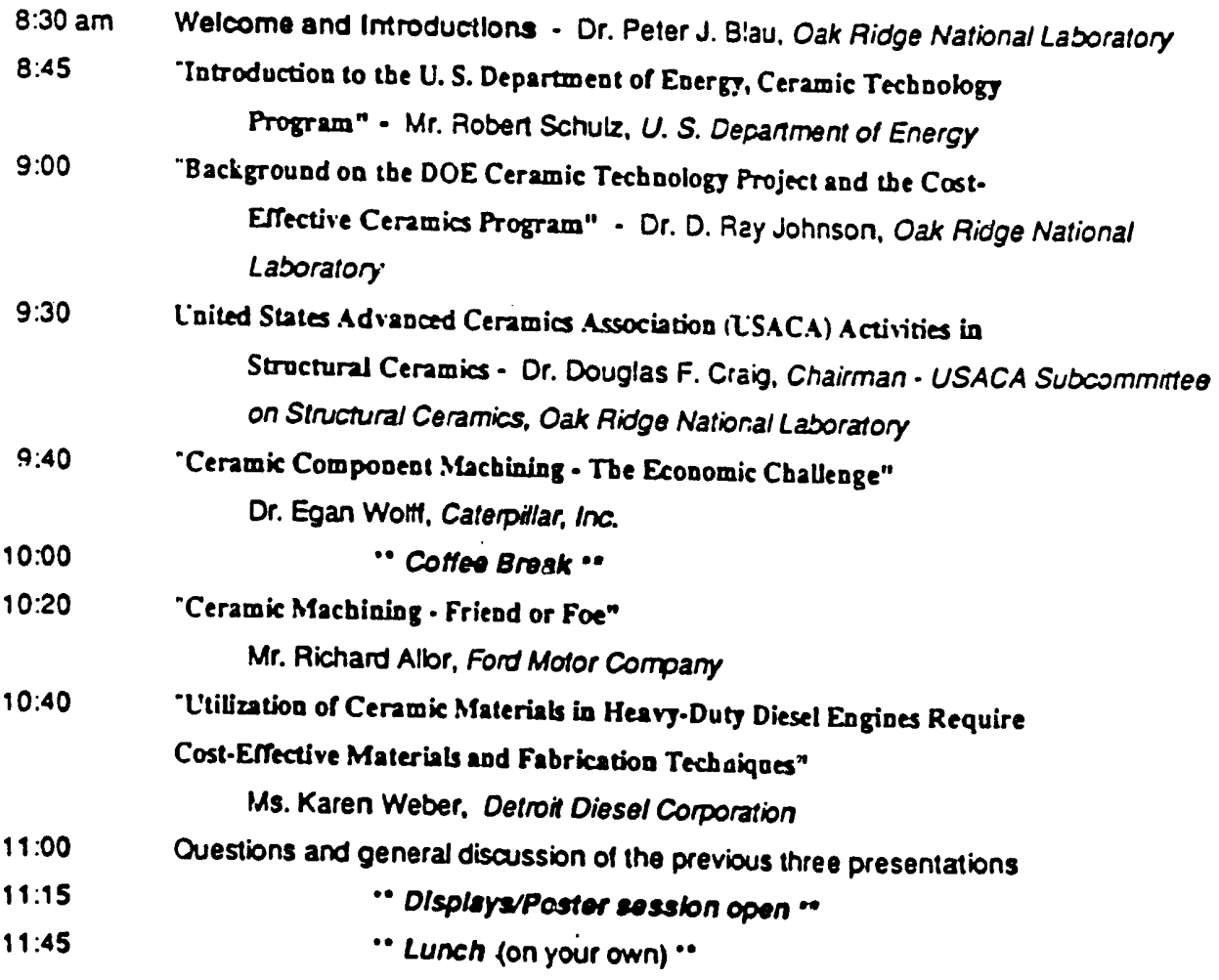

Figure 4 (a). Workshop program, page 1. 


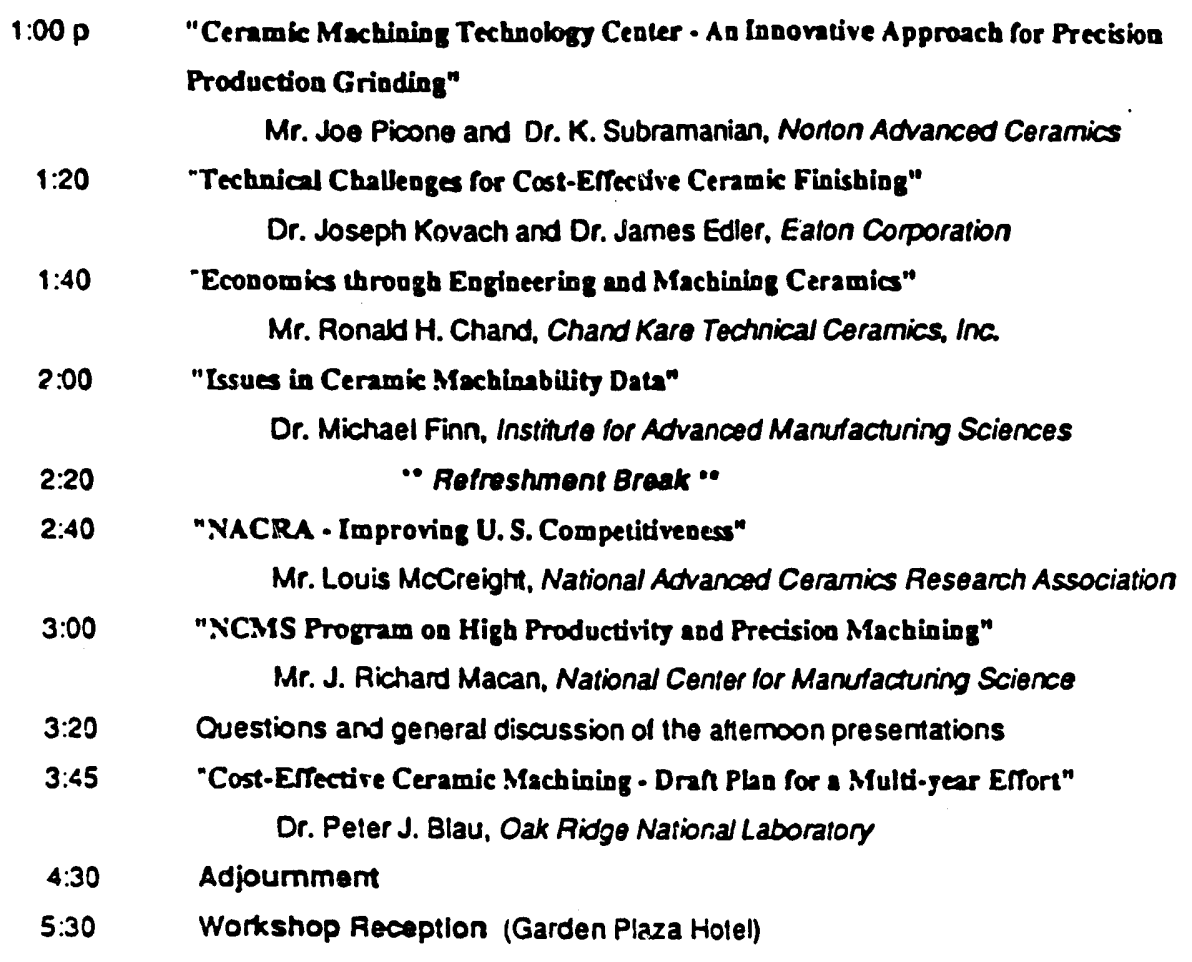

Thursday.May23:

\begin{tabular}{|c|c|}
\hline $8: 30$ a & Announcements \\
\hline \multirow[t]{2}{*}{$8: 40$} & "Department of Energy Defense Programs Activities in Machining" \\
\hline & Mr. Fred Jones, Martin Mariona Energy Systems, Y-12 Piant \\
\hline \multirow[t]{3}{*}{ 9:10 } & If Ner Ceramic Specimen Preparation Liser Center at the ORNL, \\
\hline & High-Temperature Materials Laboratorg" \\
\hline & Dr. Mat K. Ferber, Oak Ridge National Laboratory \\
\hline \multirow[t]{2}{*}{ 9:30 } & "Ceramic Machioiog at .NTST" \\
\hline & Dr. Sandy Dapkunas, National Institute for Slandards and Technology \\
\hline 10:00 & "Coffee Bresk - Poster / DIsplay Area Open ". \\
\hline $90: 45$ & Closing Session - CECM Plan Crilique - Plans for 1992 \\
\hline $11: 30$ & Workshop Adjournment \\
\hline $1: 10 p$ & Optional Tour: ORNL, High Temperature Materials Lo'oratory \\
\hline$-3: 15$ & (Bus leaves from the Garden Plaza Hotel - orereoistration required) \\
\hline
\end{tabular}

ornl

Figure 4 (b). Workshop program, page 2. 
of the various invited presentations. The talks represent six categories: program management, engine/vehicle companies, ceramic companies, machining organizations, industry groups, and related government programs. Talks were contributed by program managers from DOE and ORNL, by company representatives from Ford, Caterpillar, and Detroit Diesel Corporation, and by engineers from Norton Company and Eaton Corporation. Machining organization representatives giving talks included Chand Kare Technical Ceramics and the Institute for Advanced Manufacturing Sciences. Industry groups presenting talks included the U. S. Advanced Ceramics Association, the National Advanced Ceramics Research Association, and the National Center for Manufacturing Sciences. Related government programs from DOE/Defense Programs (DP) and from the National Institute of Standards and Technology (NIST) were presented.

\subsection{Program Management}

Robert B. Schulz, U. S. Department of Energy, Office of Transportation Materials (OTM), Ceramic Technology (CT) Program, described the management structure of DOE's Office of Transportation Technologies (OTT) and how the CECM effort relates to other programs. Fig. 5 (a) and (b) show the current structure. About 17\% of the OTT FY 1992 budget request is designated for materials and the CT Program is the major portion of the materials budget request He indicated that the R\&D funding split in the CT is about $60 \%$ to industry, $30 \%$ to government laboratories, and $10 \%$ to universities. There is a growing emphasis on cost-sharing, and more cooperative R\&D agreements (CRADA's) are expected in the future.

D. Ray Johnson, Oak Ridge National Laboratory, described the OTT Ceramic Technology (CT) Program and its new emphasis on low-cost ceramics, machining being one element of the new program emphasis. He explained how the CT Program is achieving the materials property goals established in the early 1980's and how most of the final goals [e.g., improved Weibull modulus $(\approx 20.0)$ for structural ceramics] should be achieved by 1993 . There is a strong history of industry involvement in the CT Program and this is expected to continue. He expressed concern that the costs for ceramic parts are not coming down fast enough to assure effective market penetration and that the important elements of those costs included: alternate forming and densification processes, improvement in part yield, raw material (powder) costs, and of course, ceramic machining (see Fig. 6).

Importantly, there has been a recent shift in the emphasis of the CT Program. This shift included the consideration of (1) near-term applications to current engines, (2) compatibility with conventional gasoline - as well as to alternately-fueled engines, and (3) development of ceramic components with less severe temperature requirements. Emphasis will include process economic models, efforts to improve process yields, and intelligent processing.

Douglas C. Craig, Manager of Ceramic Science and Technology at ORNL, is the recentlyelected chairman of the Structural Ceramics Committee of the United States Advanced Ceramics Association (USACA). USACA has been a leading voice for the $U$. S. ceramic industry since its inception in 1985. Dr. Craig discussed the interest that USACA has in the DOE machining effort, and cited the USACA publication "Bridging the Gap" [5]. With its six-point initiative, this publication attempts to identify key $R \& D$ issues which will lead to more rapid commercialization of ceramic parts. Point Three of the six-point program states:

"A national program is needed to develop low cost ceramics for near-term use in heat engines. Such a program would focus on ceramic machining and finishing, ceramic raw materials, alternative processes (low cost, net shape, process automation equipment development), yield 


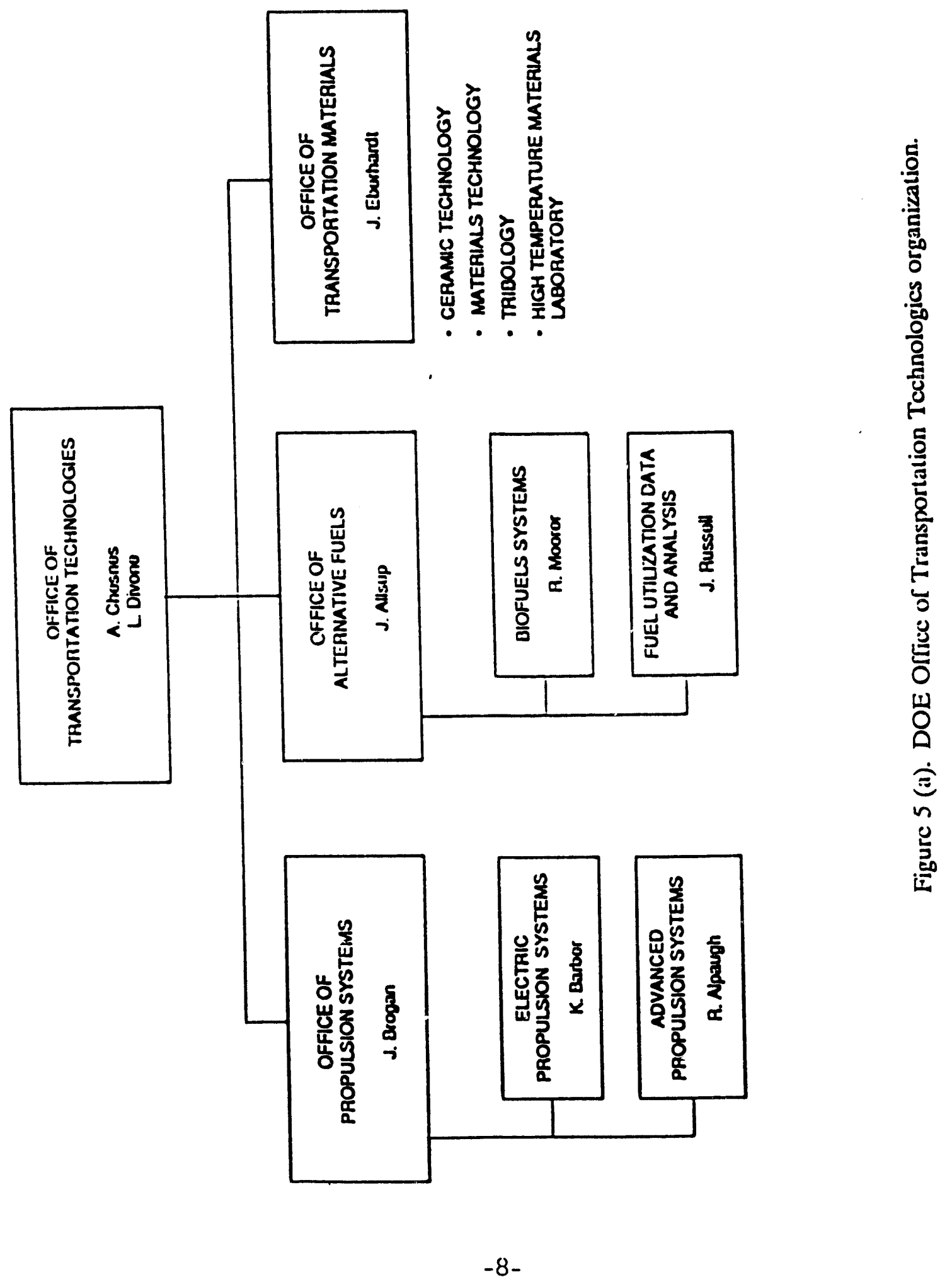



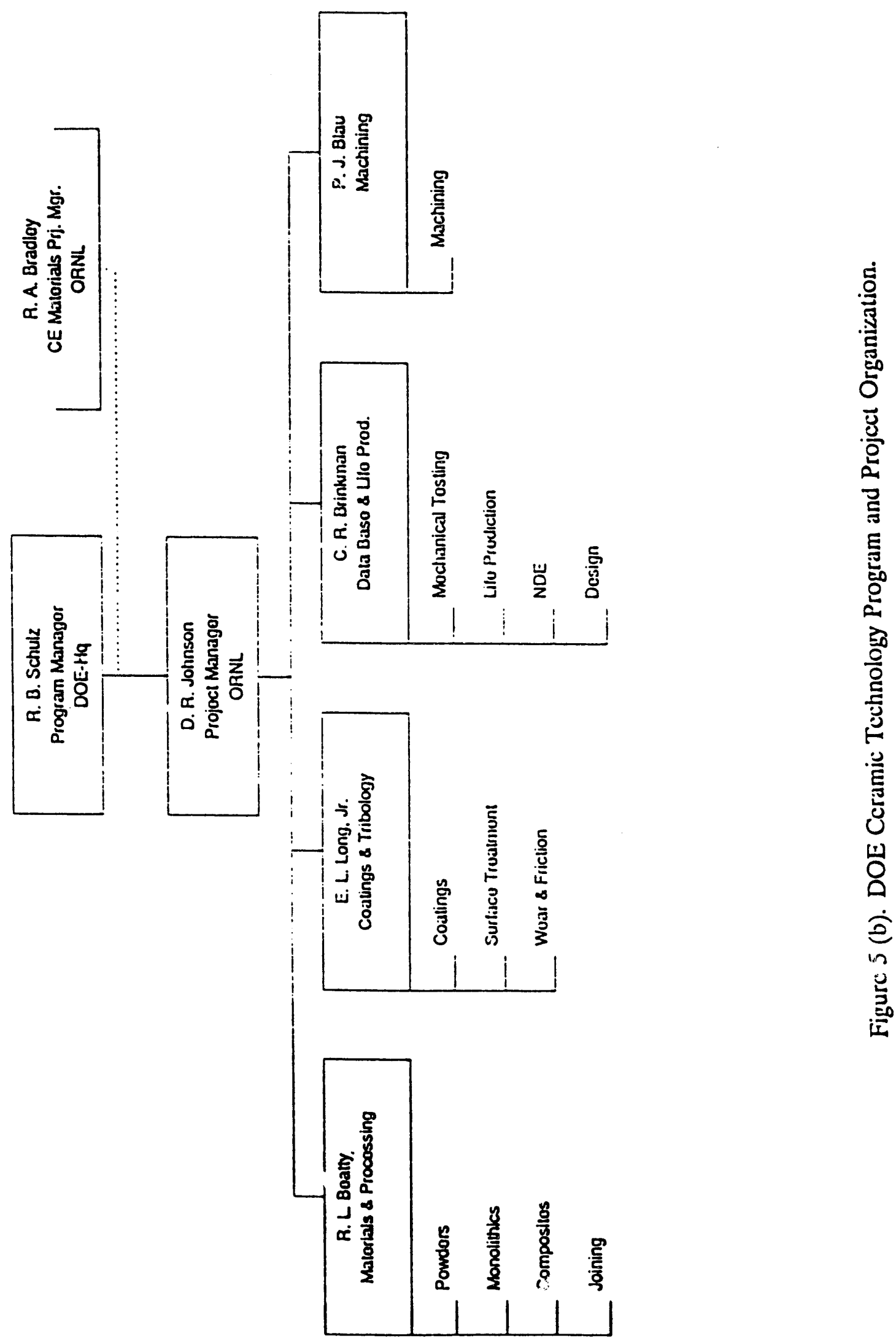


\title{
COST-EFFECTIVE CERAMICS FOR HEAT ENGINES (CECHE)
}

\author{
PROGRAM OUTLINE
}

PROCESS MODELNTG

MACHINING AND FITSHING

RAW MATERIALS (POWDERS, ADDITIVES, ETC.)

ALTERNATIVE PROCESSES

LOW COST

NET SHAPE

PROCESS EQUTPMENT DEVELOPMENT

YIELD TMPROVEMENT

STATISTICAL PROCESS CONTROL (SPC)

N.TELLIGENT PROCESSING

ECONOMIC SENSITRITY STUDIES OF ALTERNATE ENGRE SYSTEMS \& ENGINE/RIG TESTS

PERFORILAICE AND TESTING STANDARDS

DATA BASE

Figure 6. Outline for the Cost-Effective Ceramics for Heat Engines program. 
improvement (SPC), intelligent processing), testing and performance standards, data base development, and technology transfer."

The first speaker from industry was Egon Wolff, Manager of Engineering and Advanced Materials Technology, Caterpillar Inc. His first remark was the assertion that ninety percent of all machining is done to correct prior process inadequacies and that only ten percent of machining adds value. The $U$. S. automotive industry is prepared to implement ceramic components if only the cost were lower, and short-term (e.g., by the year 2000) use requires substantial cost reductions of ceramic parts. For example, the current ccst of diesel engine head plate inserts can double the cost of the engine. Key issues in ceramic machining: unacceptable cost, lack of a ceramic machine-tool supplier base, minimum R\&D activity in the area, and slow technical implementation. For the last tvio years there has been a program at Caterpillar to evaluate various types of material removal processes (mechanical, chemical, thermo-electric). Figure 7 is an overview of this extensive effort. R\&D can provide answers to many of the cost issues, but more is needed. For example, Fig. 8 shows the way that changes in the machining procedure can affect the material removal rate of magnesia-stabilized zirconia by as much as a factor of five at a given machining speed. Fig. 9 shows that the phase changes in the material surface can be affected by grinding and post-grinding anriealing. Dr. Wolff strongly advocated a team approach to attacking ceramic machining cost issues. Figure 10 indicates possible teaming partners. A steering committee would periodically review the effort and provide guidance and direction to keep it on the proper path.

Richard Allor, Ford Motor Company, indicated Ford's interest in ceramic machining began with the High-Temperature Gas Turbine Department formation in 1967 (Fig. 11). The importance of vendor experience (and even the experience of the individual machinist) in meeting flexural strength goals for ground parts was emphasized (Fig. 12 (a)) as was the effect of grinding process and wheel bond type (Fig. 12 (b)). Additional data were presented on ultrasonic and laser machining, showing the effects on these processes on the strength and Weibull modulus of the machined parts. Fig. 13 shows the advaniages of one-pass grinding on the estimated cost of a zirconia-toughened alumina cam roller follower ( 2 million parts run). Mr. Allor also described the importance of the position of the coolant nozzle with respect to the cutting wheel, a factor which can significantly reduce the diamond wheel wear. A summary of his findings is given in Fig. 14.

Ron Ellswood and Karen Weber, Detroit Diesel Corporation, discussed (1) competitiveness within the heavy-duty diesel engine community, (2) cost-effectiveness (break even vs. added value), and (3) requirements and specific examples. In the near-term, break even is important, but to be economically viable in the longer-term, it is important that added value be achieved. Figure 15 (a) and (b) represent heavy-duty diesel engine materials requirements. The 1994 emissions requirements for engines is a major concern and a driving force for many of the decisions reing made on engine designs and materials. Fig. 16 shows some projected requirements for ceramic parts production for both on and off-highway engines in 1993. Target costs for silicon nitride cam roller followers range from $\$ 3$ to $\$ 4$ each by 1995 , and the target costs for silicon nitride valves range from $\$ 15$ to $\$ 35$ each. There is a real need for "rig-type" accelerated laboratory testing of ceramic components. Statistical process control will be used to demonstrate the capability to meet parts requirements and permit ramping up to high-volume production.

Joe Picone, Norton Company, described the newly-established (July 1990) Ceramic Machining Technology Center (CMTC) at Worcester, Massachusetts. CMTC's services are provided on a contractual basis to aid in prototype development, preproduction planning, and to provide turnkey or custom-engineered grinding systems. The company has assembled state-of-the-art grinding equipment to provide a resource for ceramic grinding technology development, and to facilitate 


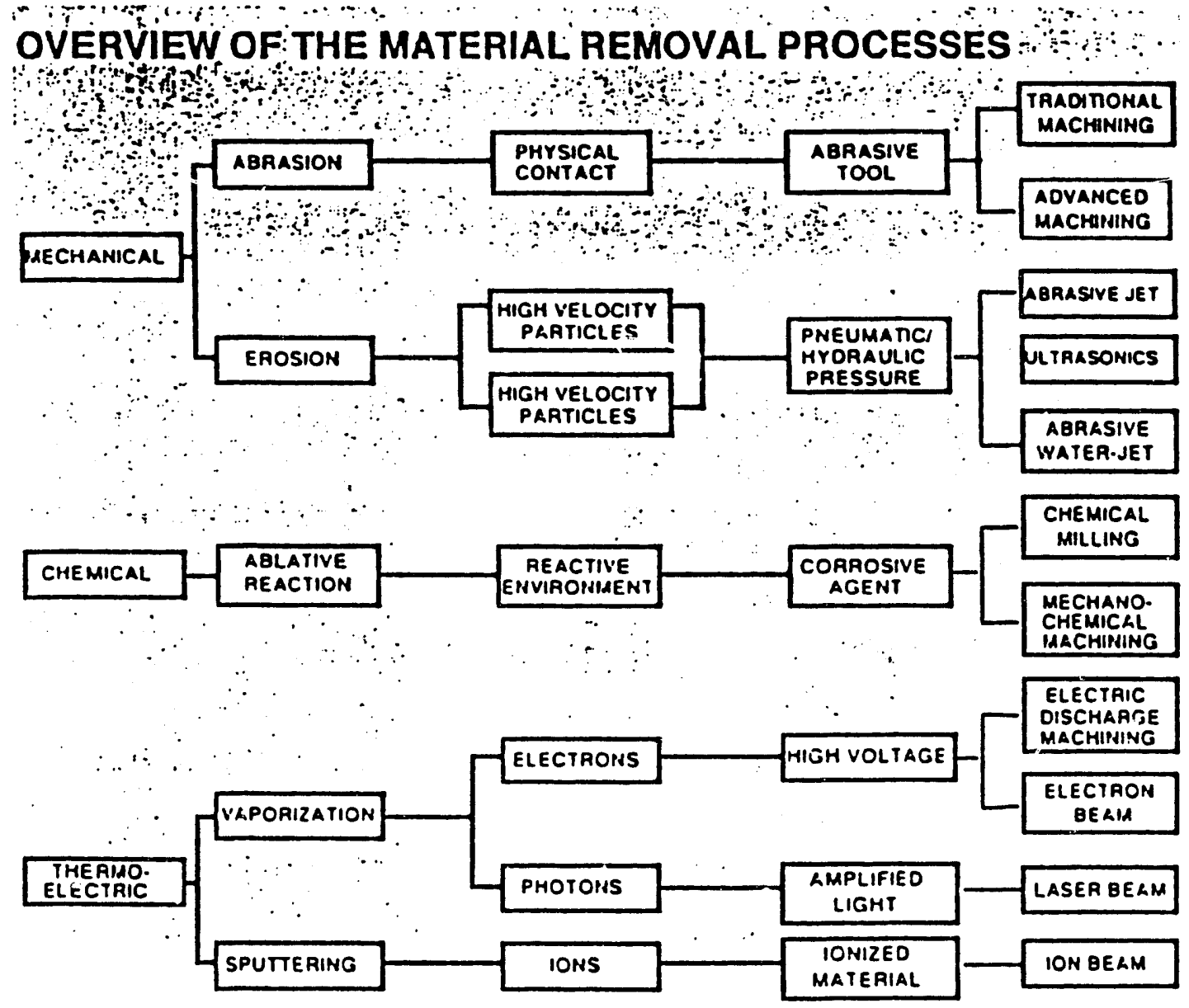

Figure 7. Material removal process analysis (E. Wolff) 


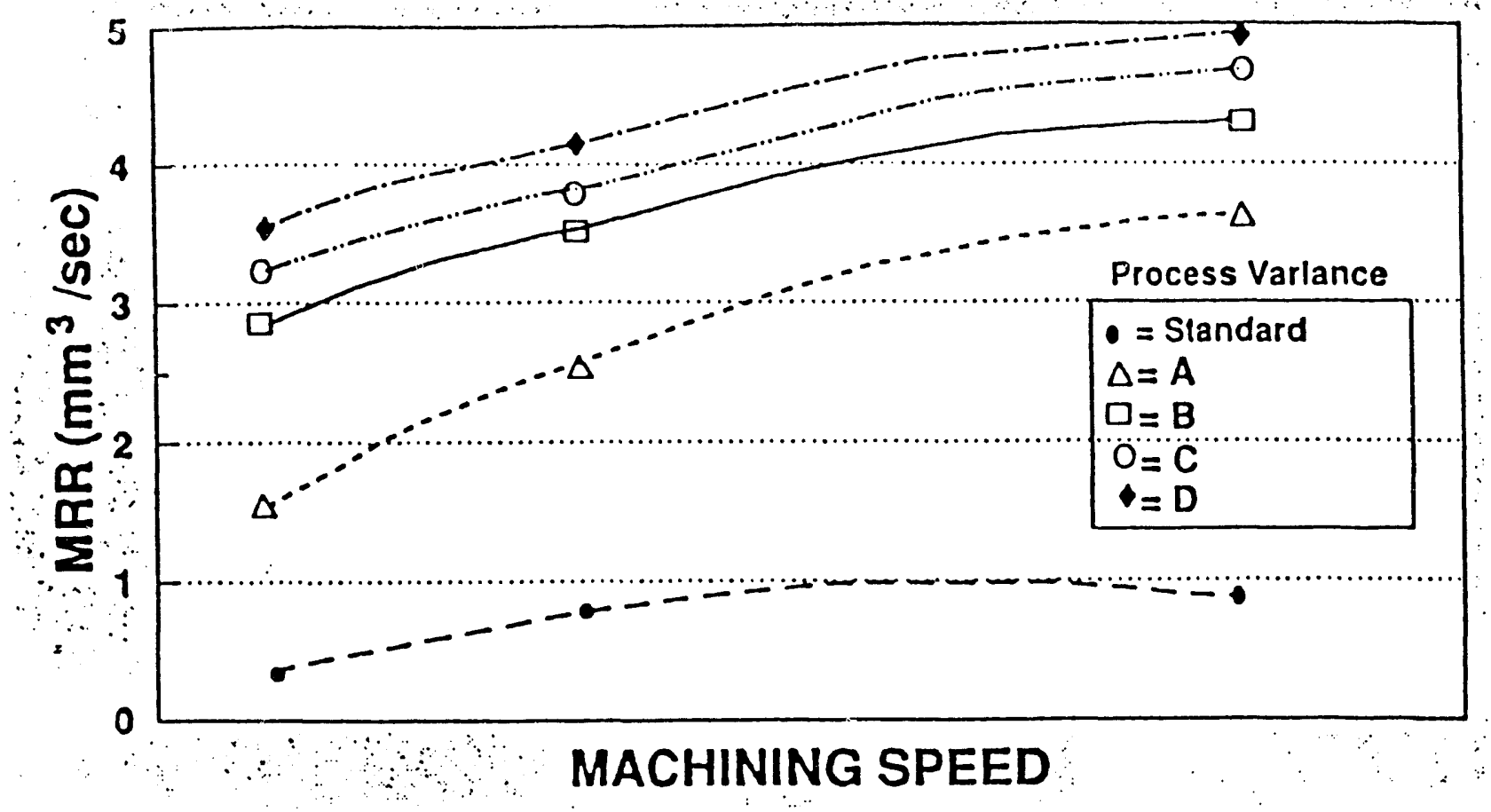

Workplece Materlal - Magnesla Slabllized Zrconia Machining Pressure Held Constant

Figure 8. Relationship between surface speed and material removal rate (E. Wolff).

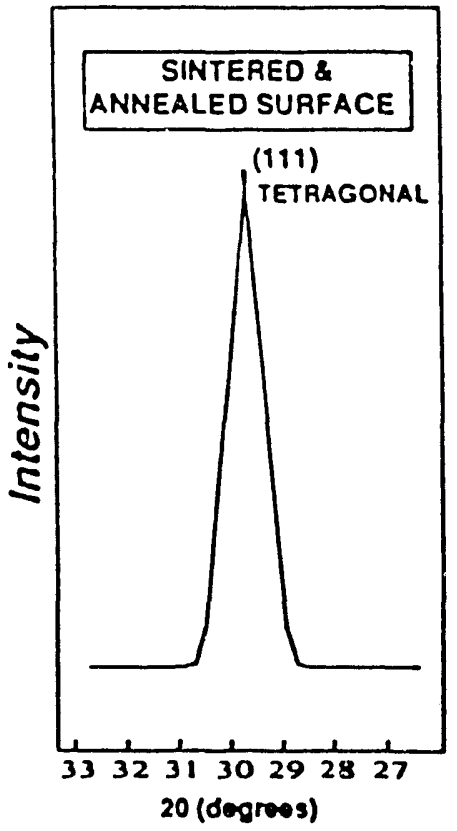

(a)

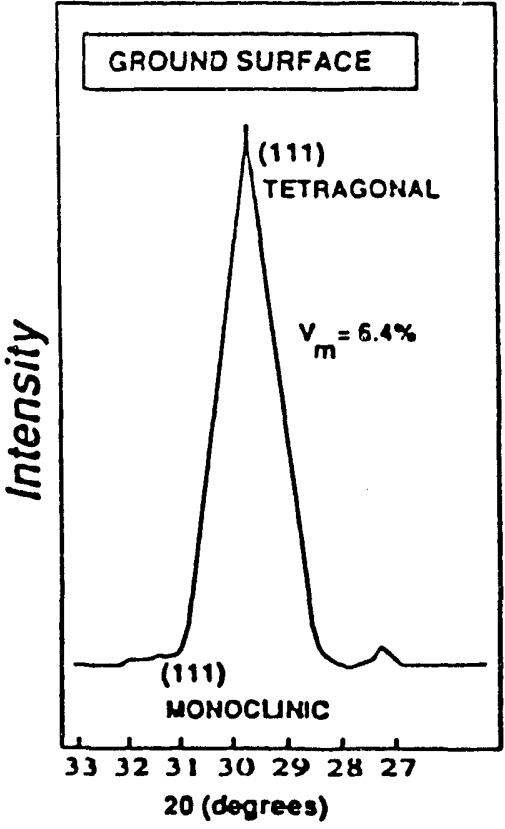

(b)

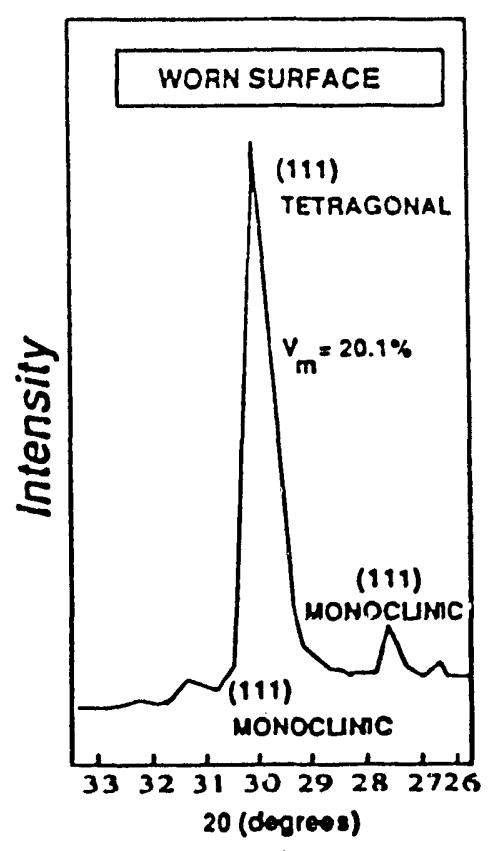

(c)

\section{XRD Traces of 2Y-TZP}

Figure 9. Effect of processing on the phase content of zirconia (E. Wolf). 


\section{PROGRAM EFFORT}

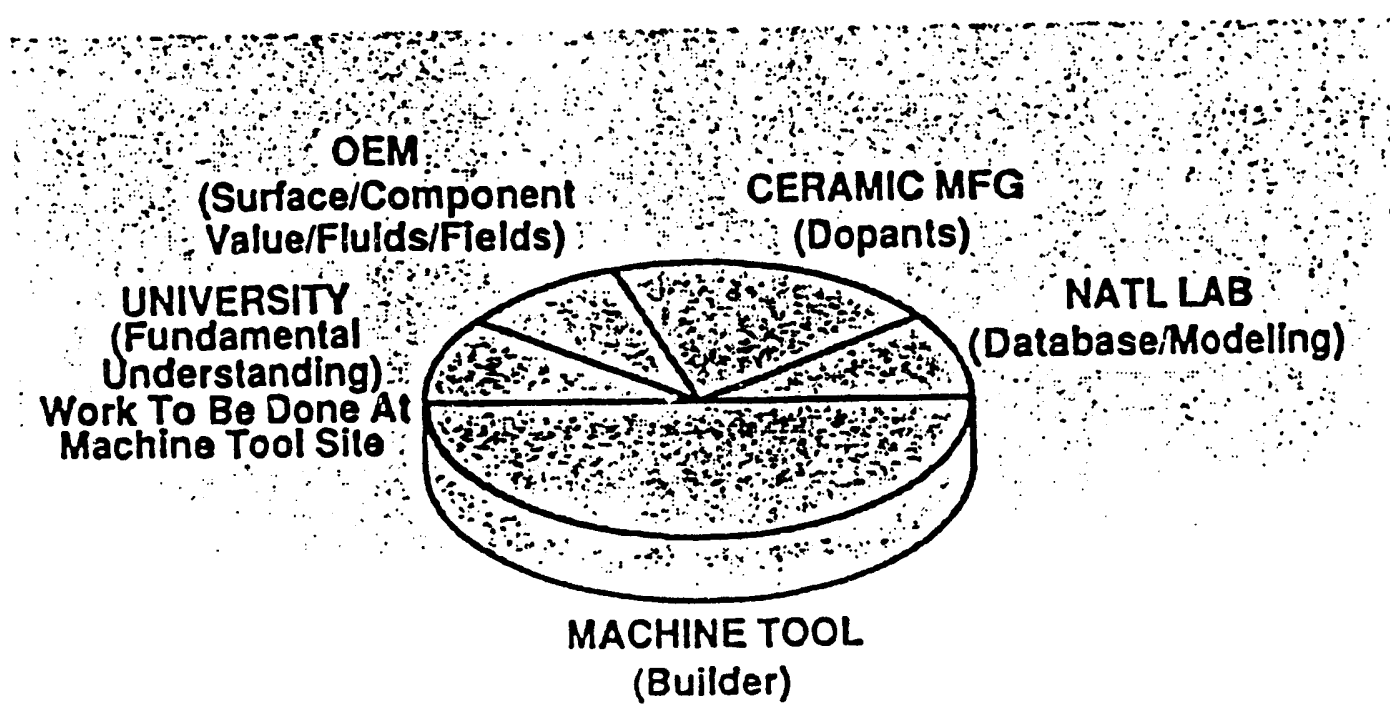

Figure 10. Suggested composition of a cooperative program ceramic machining (E. Wolff). 
1967

High Temperature Gas Turbine Department Formed

1971 - 1977 DARPA Sponsorship of Ceramic Gas Turbine Project

1979 - 1987 DOE Sponsorship of AGT Turbine Project as Subcontractor to Garrett/AiResearch

1980 Demonstrated Functional Ceramic Turbocharger

1982 - 1984 Developed Silicon Nitride Cutting Tool

1985 Licensed iscar to Produce Cutting Tools

1985 - 1987 Supported Adiabatic Diesel Engine Program

1986

Formed Ceramic Joint Venture with Ceradyne Corporation

1987 - Automotive and Manufacturing Applications

Present

Emphasized

Figure 11. Capsule history of Ford's involvement with ceramic components (R. Allor). 


\section{Metal Bond \\ Norton NC 132 \#1312}
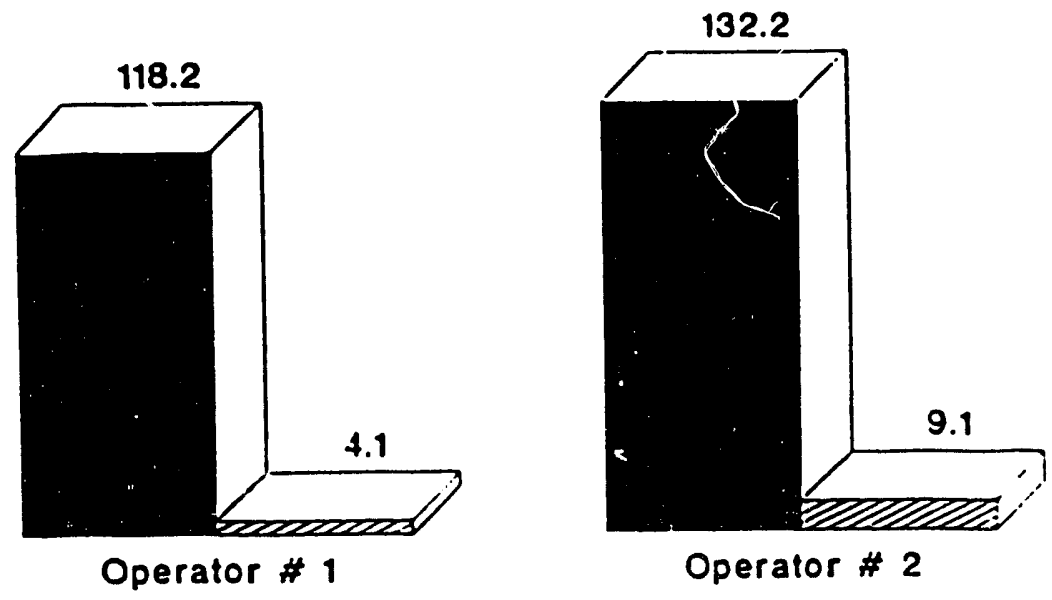

Sirength (KSI) Weibull Slope

\section{Diamond Wheel Bond Study Norton NC 132 \#1334}

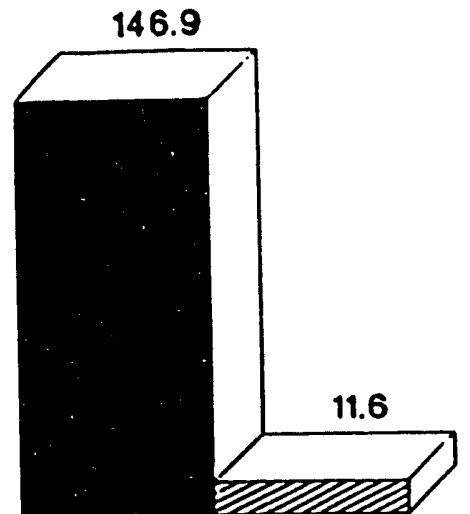

Resin

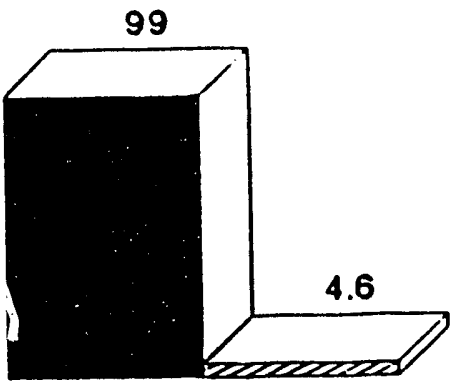

Metal

Bond Type

strength (KSI) Weibull Slope

Figure 12. Effect of machine tool operator (a) and wheel bond type (b) on the strength and Weibull modulus of machined silicon nitride ( $R$. Allor). 
ESTIMATE OF COSTS FOR A ZTA CAM ROLLER

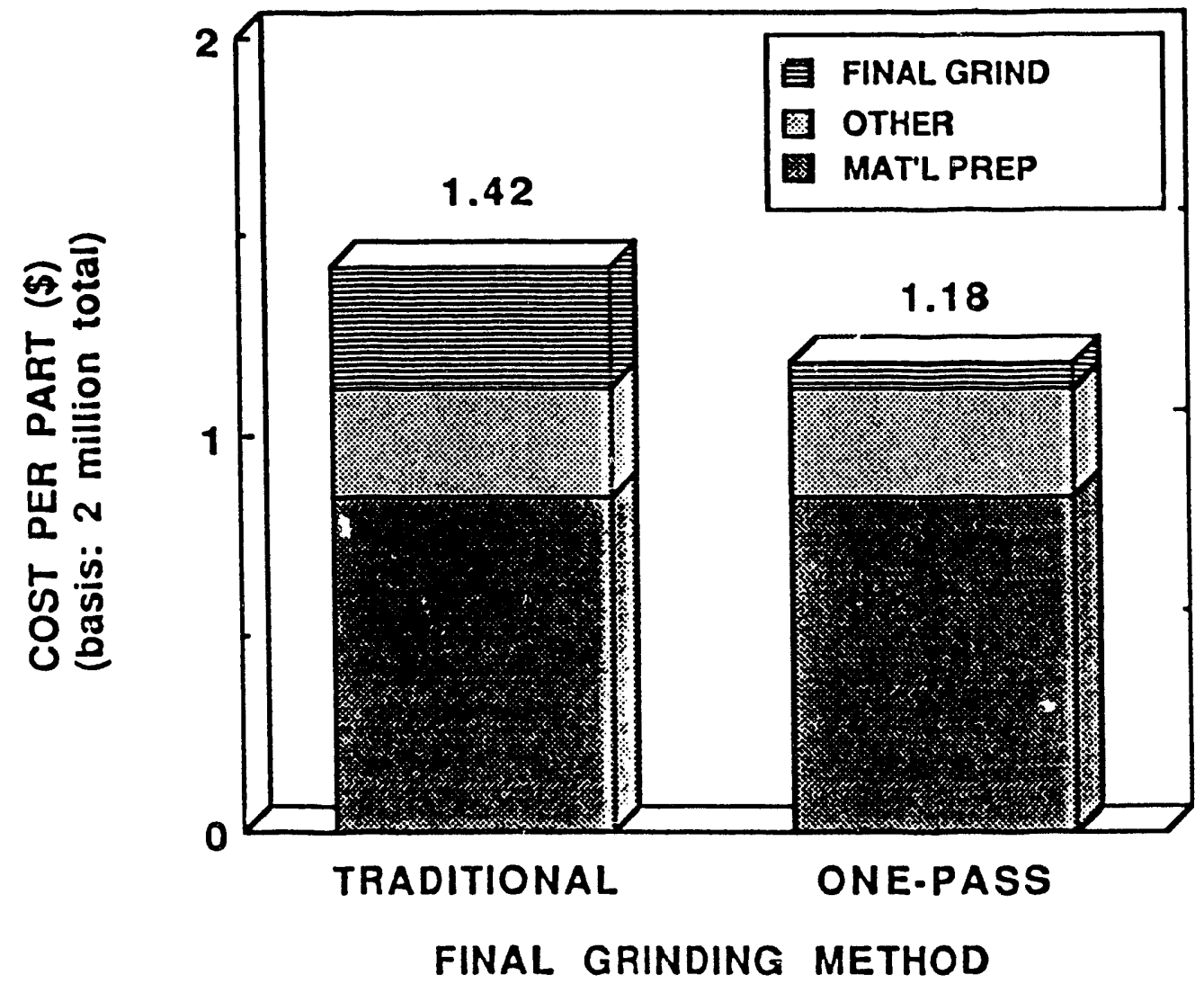

Ref: R. Albr

Figure 13. Comparison of costs estimated for a zirconia-toughened alumina (ZTA) cam roller final ground by two different methods (R. Allor). 


\section{Ceramic Machining Conclusions}

- Skill and experience is important

- Metal bond grinding wheels may reduce strength

- Grinding direction will effect strength

- Too fine of diamond may reduce strength

- Downfeed rate may be increased

- The diamond wheel type is important to cost

- Coolant location may reduce diamond wear

- Cost of core drilling can be reduced

- All material removal methods should be confirmed with strength data

Figure 14. Conclusions from Mr. Allor's presentation on ceramic machining experience. 
Heavy-Duty Diesel Engine Material Requirements

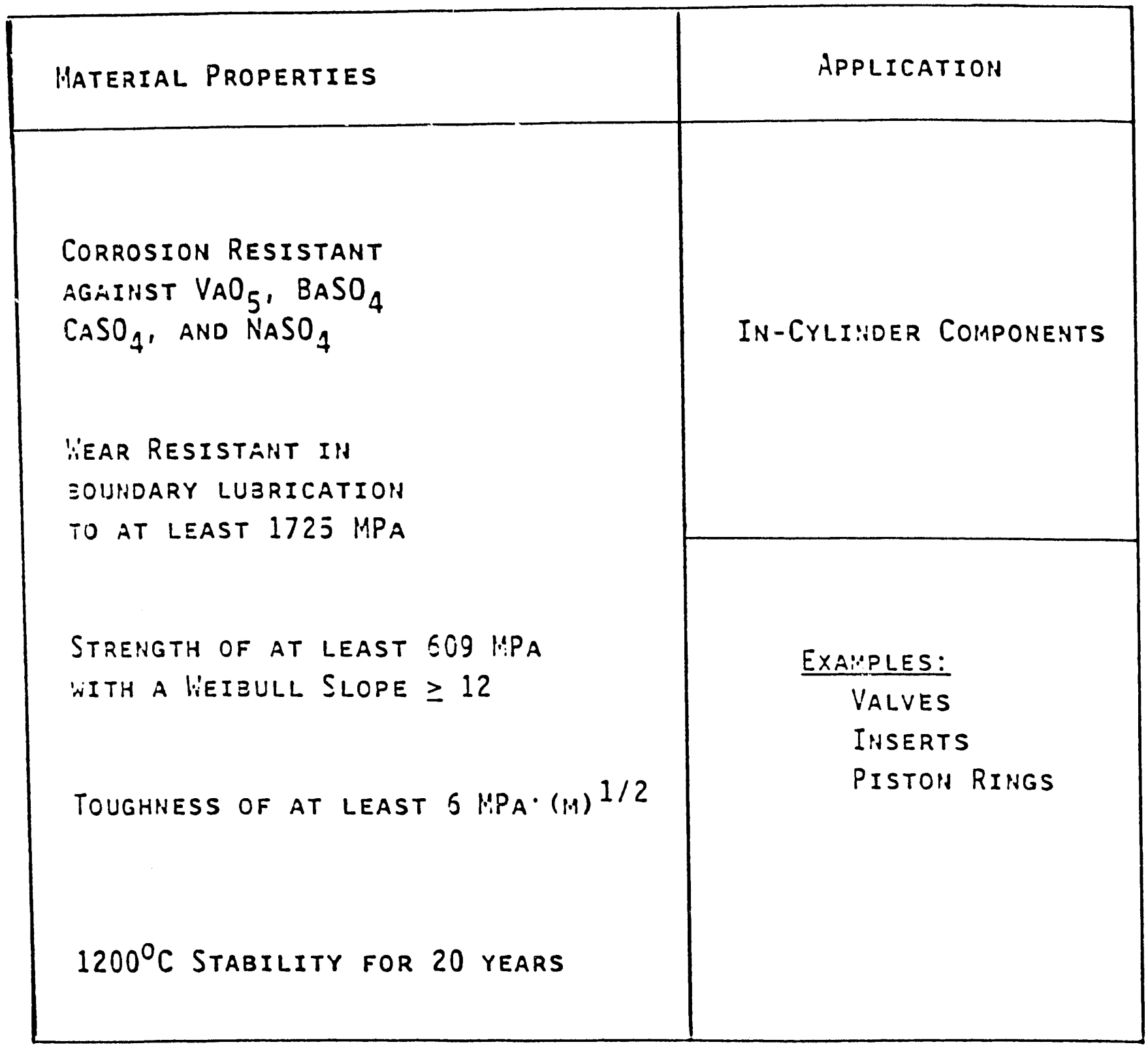

Figure 15 (a). Engine material requirements: for the heavy-duty diesel (K. Weber and R. Ellswood). 
Heavy-Duty Diesel engine Material Requirements

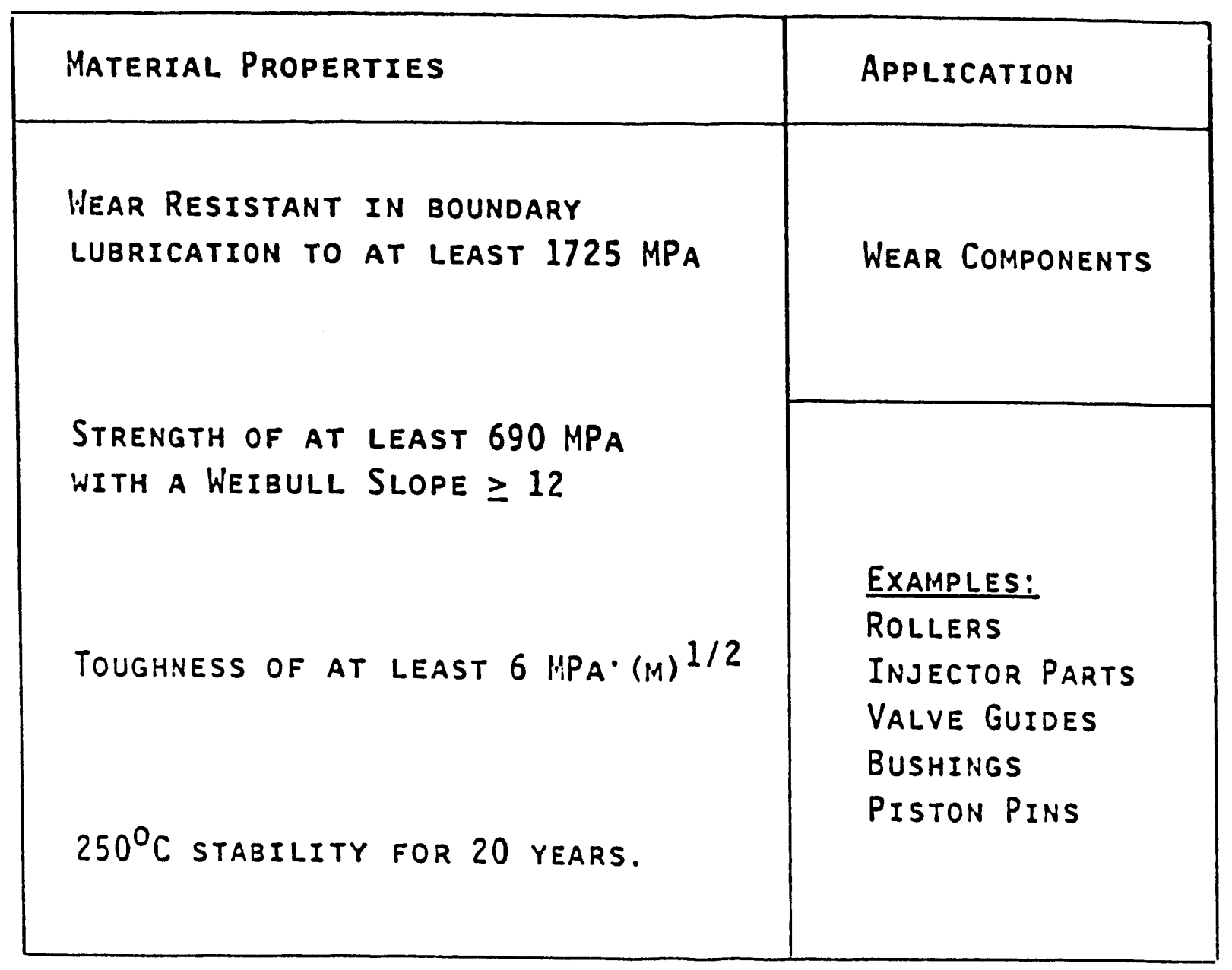

Figure 15 (b). Engine material requirements for the heavy-duty diesel (K. Weber and R. Ellswood). 
1993

\begin{tabular}{|c|c|c|}
\hline COMPONENT & O!N-HIGHINAY & OFF-HIGHTAY \\
\hline ROI.LERS & $75 \mathrm{~K} / \mathrm{MONIH}$ & $15 \mathrm{~K} / \mathrm{BONTH}$ \\
\hline VALVES & $200 \mathrm{~K} / \mathrm{MONTH}$ & $\Xi \mathrm{X} / \because$ ONTH \\
\hline PISION RINGS & $27 \mathrm{~K} / \mathrm{MONTH}$ & $4 \mathrm{~K} / \mathrm{MONTH}$ \\
\hline INSERIS & 200K/MO:IIH & 5:X/OONTH \\
\hline BUSHINGGS & $2 \equiv-125 \mathrm{~K} / \mathrm{S}: 0: 1 I: \mathrm{I}$ & EX/@ONTH \\
\hline VALVE GUIDES & IOOK/MONIA & $5 X /: O N T A$ \\
\hline $\begin{array}{l}\text { INJECTOR } \\
\text { COMPONENTS }\end{array}$ & $25: K / M O N T H$ & 5:/XONT: \\
\hline
\end{tabular}

Figure 16. Estimated production numbers for ceramic parts for on and off-highway vehicles (K. Weber and R. Ellswood). 
developing partnerships with original equipment manufacturers and suppliers to work on proprietary projects in machining.

The next presentation was made by James Edler and Joseph Kovach, Eaton Corporation. Edler began by enumerating three challenges for his company: (1) the business challenge, (2) the product challenge, and (3) the manufacturing challenge. Each was described. Other challenges are listed in Table 1. Kovach presented data from a series of machining experiments to illustrate variability in strength from one part to another, effect of material removal rate (MRR) on part strength, the effeit of slotting on wheel performance, and the effect of wheel grit size on strength differences from part-to-part. He also made a series of general observations about the effects of grit size on MRR and finish. Three cost reduction challenges were given: (1) increased wheel life (Gratio), (2) increased MRR, and (3) reduced wheel dressing time. Kovach advocated more emphasis on developing both fundamental and practical models for ceramic machining processes. Finally, he discussed some of the advantages foreseen for using creep-feed grinding over conventional plunge grinding. Potential, suggested routes to process enhancement, recommended by the two speakers, are shown in Fig. 17.

Ronald Chand, Chand Kare Technical Ceramics, began by stating that ceramic machining was their only business so they are highly-focussed on cost-reduction and process efficiency measures. He provided a partial listing of cost drivers for ceramic machining which included:

- near-net shape capability limitations

- green machining limitations

- extra machining requirements of the reaction layer

- mis-application of diamond wheel machining practice to ceramic component machining

- unavailability of specialized machines and machine tools

- coolant control and recovery

- commitment to volume production

- lack of serious commitment by machining vendors and others to fundamental machining studies

- component design without respect to machining requirements.

Figure 18 shows the difference between existing processes and engineered processes for ceramic machining. An important issue is economy of scale. For a given part (e.g., an injector link), the per part price of machining 25 prototype parts was nearly 70 times higher than the projected per part cost for making 1000 parts in production.

Michael Finn, Institute of Advanced Manufacturing Sciences, first presented an overview of IAMS, then described their interest and background in ceramic machining. There are five centers at LAMS, one of which is the Center for Machining and Machine Tool Technology (M2T2) (See Fig. 19, 20). Finn highlighted several active projects within M2T2 (Fig. 21). A plan for collecting and developing data for ceramic machining was described (Fig. 22).

Louis McCreight, National Advanced Ceramics Research Association, described the organization and function of NACRA. It was established as an outgrowth of a National Academy of Sciences study and became a non-profit, public benefit corporation in California in 1988. Fig. 23 shows the concept of NACRA's operation and Fig. 24 summarizes its administration. NACRA's current approach to cost-effective ceramic machining is shown in Fig. 25. 
Table 1.

CHALLENGES IN USING CERAMICS IN ENGINES

(Ref. Edler and Kovach, Eaton Corporation)

Challenge

Global Finishing for

Engine Ceramics

Specific Finishing

Cost-Reduction

Quality
Items

low-cost

high-volume

flexible manufacturing

better OSHA requirements

non-polluting

automation

use of non-skilled personnel

consistent, high quality

measurable control characteristics

minimize capital requirements

use available machinery

convert metalworking equipment

reduced costs

increased quality

improved process understanding

machine tool/process optimiz.

increased wheel life (G-ratio)

increased material removal rates

reduced dressing time

maximum surface integrity

minimize surface roughness

achieved surface form/tolerance

develop inspection techniques 


\section{MACHINE TOOL/PROCESS OPTIMIZATION}

\section{Utilization of Existing Equipment}

Aternative Wheel Truing/Dressing Systıms

- Improve Form Dressing Capabilitios

- Reduce Dressing Time

- Increase Dressing Procision \& Accuracy

Increased Rigidity \& Precision

Controlled Compliance

Reduced Setup \& Fixturing

Improven Controls \& Sensors

- Rapid Whoel Withdraw

- Adaptivo Contral

- In-Process Inspection (Ukrasonics, Elc.)

- Combined Processes

- MEEC, COMMEC

\section{Alternative Process Utilization}

- Ultrasonics

- Losso Abrasives

- Now Sispertinishing Techriques

Figure 17. Factors in machine tool optimization (J. Edler and J. Kovach). 


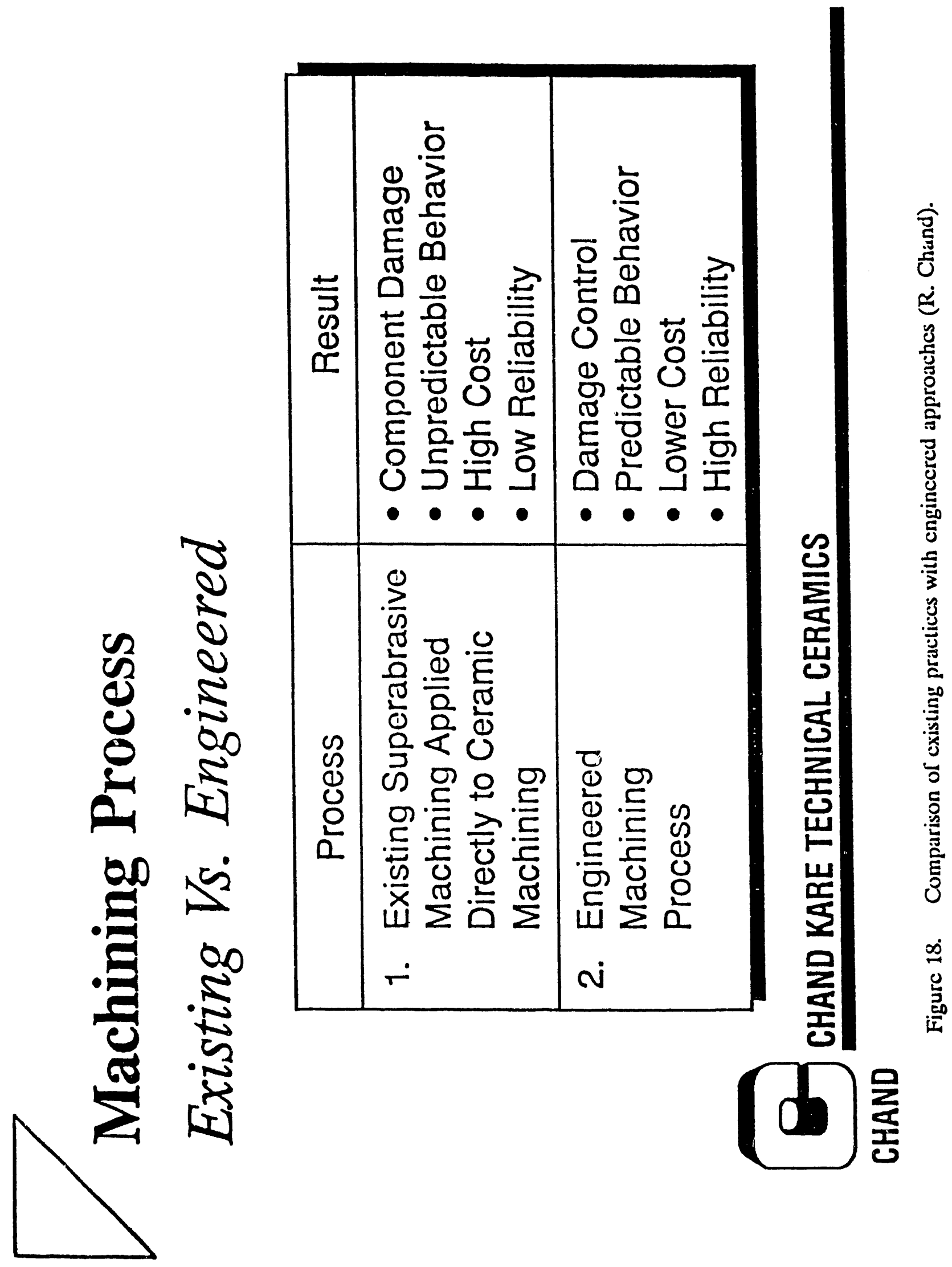




\section{Machining and Machine Tool Technology (M2T2)}

\section{Overview}

- Mission

Provide service to Industry which Improves

Manufacturing Quality and Competitiveness via

Better Engineered Processes

- Staff

- Director

-Dr. Wm. Zdeblick

- Project Engineers -Mr. John Pfeiffer

-Mr. Mike Owens

-Mr. Mike Finn

-Mr. Guy Hughes

- 3 Lab Technicians

- 2 Part-Time Associates

-Miami U. Professor

-Ford Retiree

-Mr. Mryon Schmenck

-Mr. Bob Shumway

- Temporary Grad Students \& Technicians

- Services

- Certification Testing

- Contract Research \& Engineering

- Consortia R\&D

Figure 19. Structure of the Center for Machining and Machine Tool Technology at IAMS (M. Finn). 


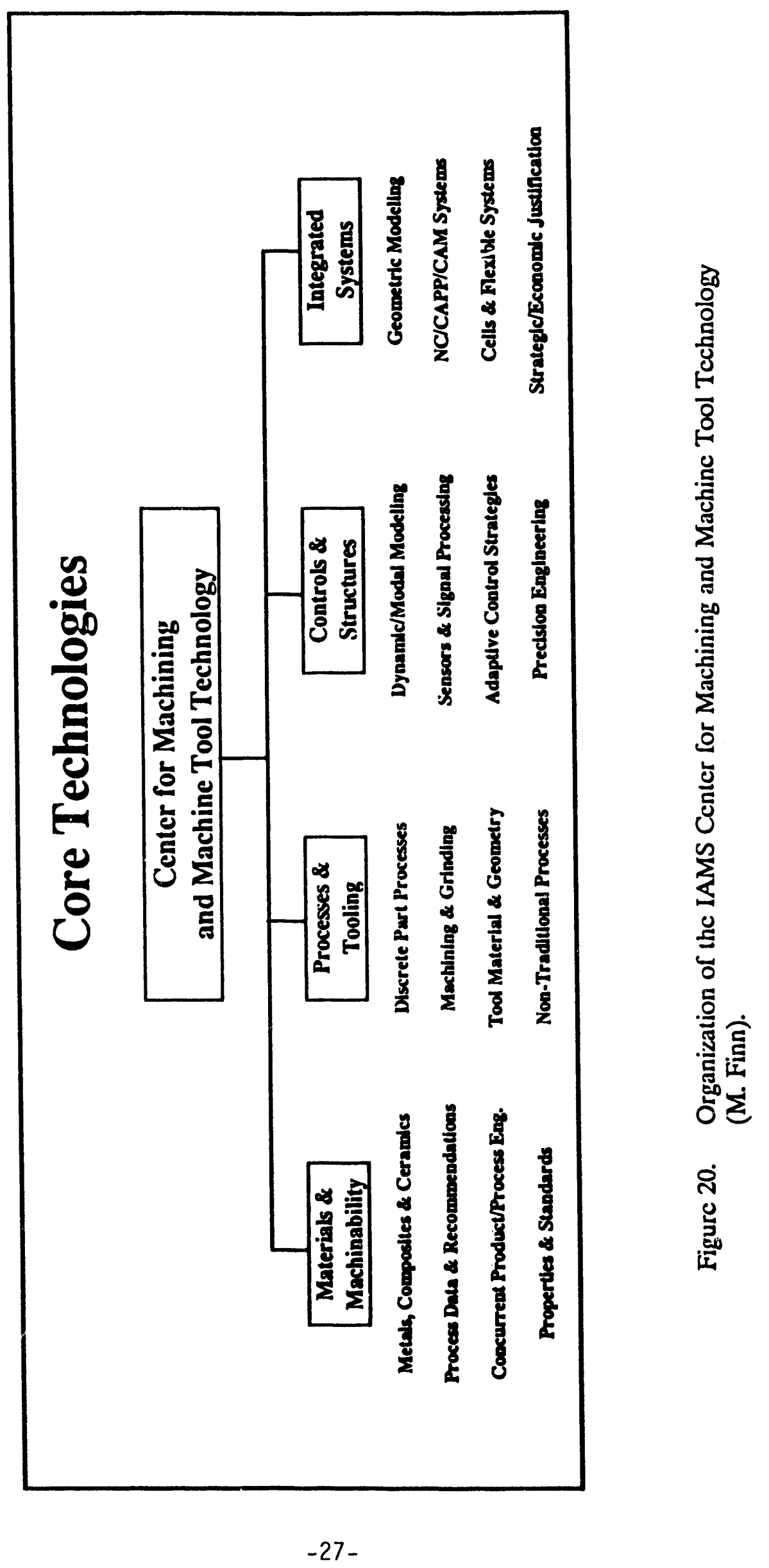




\title{
Center for Machining and Machine Tool Technology
}

Focus:

\author{
Improved Manufacturing Quality \\ through \\ Better Engineered Processes
}

APPROACH:

* Test , Evaluate \& Verify

$*$ Understand \& Model

* Monitor \& Control

* Automate for Consistency

SCOPE:

* Discrete Part Processes \& Equipment * Material Separation Processes * Precision Manufacturing Equipment * Integrated Workcells

Figure 21. Focus, approach, and scope of the IAMS Center for Machining and Machine Tool Technology (M. Finn). 


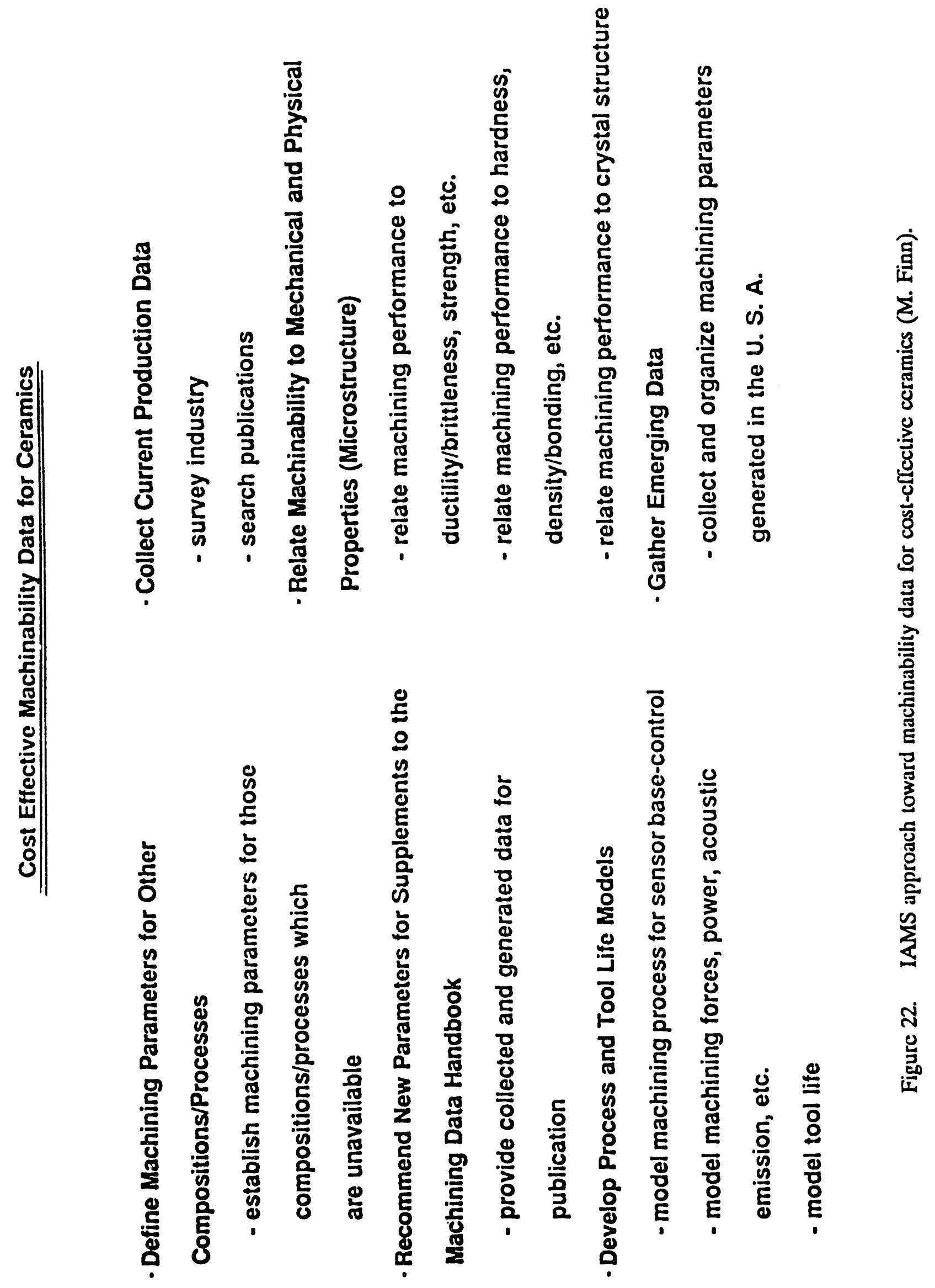




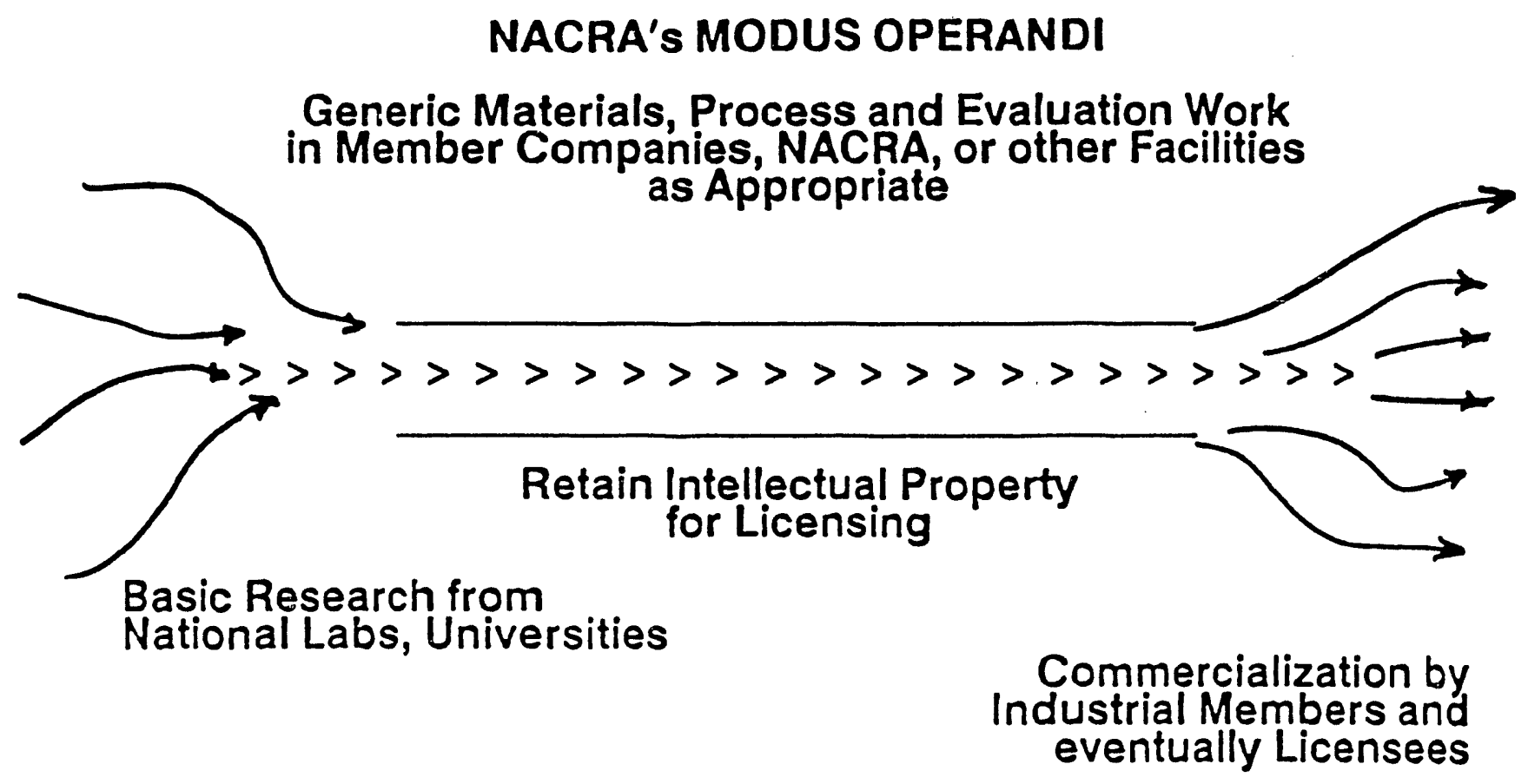

Figure 23. Diagram of the way in which NACRA develops technology (L. McCreight). 


\section{NACRA SUMMARY \\ National Advanced Ceramic Research Association}

-An Industrial Association to aid commercialization of Advanced Ceramics.

- Membership open to any U.S.-based company involved in or interested in Advanced Ceramics.

-Annual dues are $\$ 5000$.

- Membership includes a seat on Board of Directors and on Technical Advisory Committee.

-Participation in research projects is voluntary and requires financial and technical involvement.

- Consortium approach to research programs greatly leverages each participant's financial contribution.

\section{Business Office}

2200 Amapola, Suite 101, Torrance, CA 90501

(213) 782-2490 FAX (213) 533-1068

- Louis R. McCreight, President, (213) 548-6154 2763 San Ramon Dr., Rancho Palos Verdes, CA 90274

- Dr. Carl E. Frahme, Exec. Dir., Phone/FAX (805) 270-9204

8737 Vientos Dr., Leona Valley, CA 93551

Figure 24. Summary of NACRA mission, membership, and approaches to technology development (L. McCreight). 


\section{NACRA MACHINING OF ADVANCED CERAMICS}

\section{- ROBUST DESIGN OF MATERIALS, PROCESSES, AND COMPONENTS TO YIELD NET SHAPE}

- DESIGN TO

MINIMIZE MACHINING

AUTOMATED HANDLING OF PARTS IN \& OUT OF MACHINING

- INNOVATIVE HIGH SPEED MACHINING WITHOUT DAMAGE TO PARTS

\section{BROAD INTERDISCIPLINARY SYSTEMS APPROACH}

Figure 25. NACRA approach to a cost-effective machining program for advanced ceramics (L. McCreight). 
J. Richard Macan, National Center for Manufacturing Sciences, described that organization and discussed its new initiative in conjunction with the Department of Energy, Defense Programs (Fig. 26). The initiative was a result of a year and a half study and identified sixty-eight key issues. NCMS, now a consortium of over $100 \mathrm{U}$. S. corporations, was itself incorporated in 1986, aided by the National Cooperative Research Act of 1984 which enabled firms to legally engage in joint precompetitive research with no antitrust implications. Other participants in NCMS programs include the National Machine Tool Builders Association and the U.S. Air Force, Manufacturing Technology Directorate. Macan described proposed work in the areas of high-productivity and precision machining, gaging and sensing, next generation controller, feature-based programming, and a machine accuracy handbook.

Fred Jones, Martin Marietta Energy Systems (Y-12 Plant), described the Department of Energy, Defense Program's significant interest in bringing formerly classified machining technology into the U. S. commercial sector. Much of what he said related to the project shown in Fig. 26, which was facilitated and motivated by the 1989 Technology Transfer Act. There is a strong emphasis on modernization. Plans are to establish a machining facility ("Technology Deployment Center") in the Oak Ridge area in which industrial participants could learn machining difficult materials efficiently on state-of-the-art machine tools. Other issues involve developing new, stiffer machine tools. Discussions are underway to develop cooperative arrangements between the DOE, Offices of Transportation Materials and Defense Programs.

Matt Ferber, Head of the Mechanical Properties User Center, ORNL, described plans for a new Ceramic Specimen Preparation User center in the ORNL High Temperature Materials Laboratory. Emphasis of the new center, to be opened in the fall of 1991, is on establishing machining and gaging practices for structural ceramic, mechanical-properties test specimens. Ferber described techniques used to evaluate the stresses in buttonhead tensile specimens as well as the importance of meeting critical dimensional tolerances. He briefly described the User Center philosophy as regards industrial participation in both proprietary and non-proprietary projects.

Sandy Dapkunas, National Institute of Standards and Technology, described his organization's current programs in ceramic machining. NIST conducted two industry workshops within the past year and has recently completed an assessment of needs in the area of ceramic machining. The assessment, identifies grinding as a major portion of machining cost and identifies research needs in the following areas:

- novel processes to reduce grinding time and surface damage

- data for cost estimation

- identification of optimum grinding parameters for specific materials

- role of machine tool, grinding wheel, grinding fluid characteristics

- machining mechanisms

- on-line sensing of workpiece condition

The NIST ceramic machining assessment, authored by S. Jahanmir, A. W. Ruff, M. B. Peterson, and L. K. Ives, will be published as a NIST report in the near future. NIST is now beginning a study on the chemical effects of cutting fluids ("tribochemical machining") on cutting of ceramics, an outgrowth of their previous work on tribolony of ceramics. Initial results are encouraging (Fig.'s 27-28). There is also an on-going activity called "Optimization of Grinding Parameters" which is being conducted with industrial collaboration. 


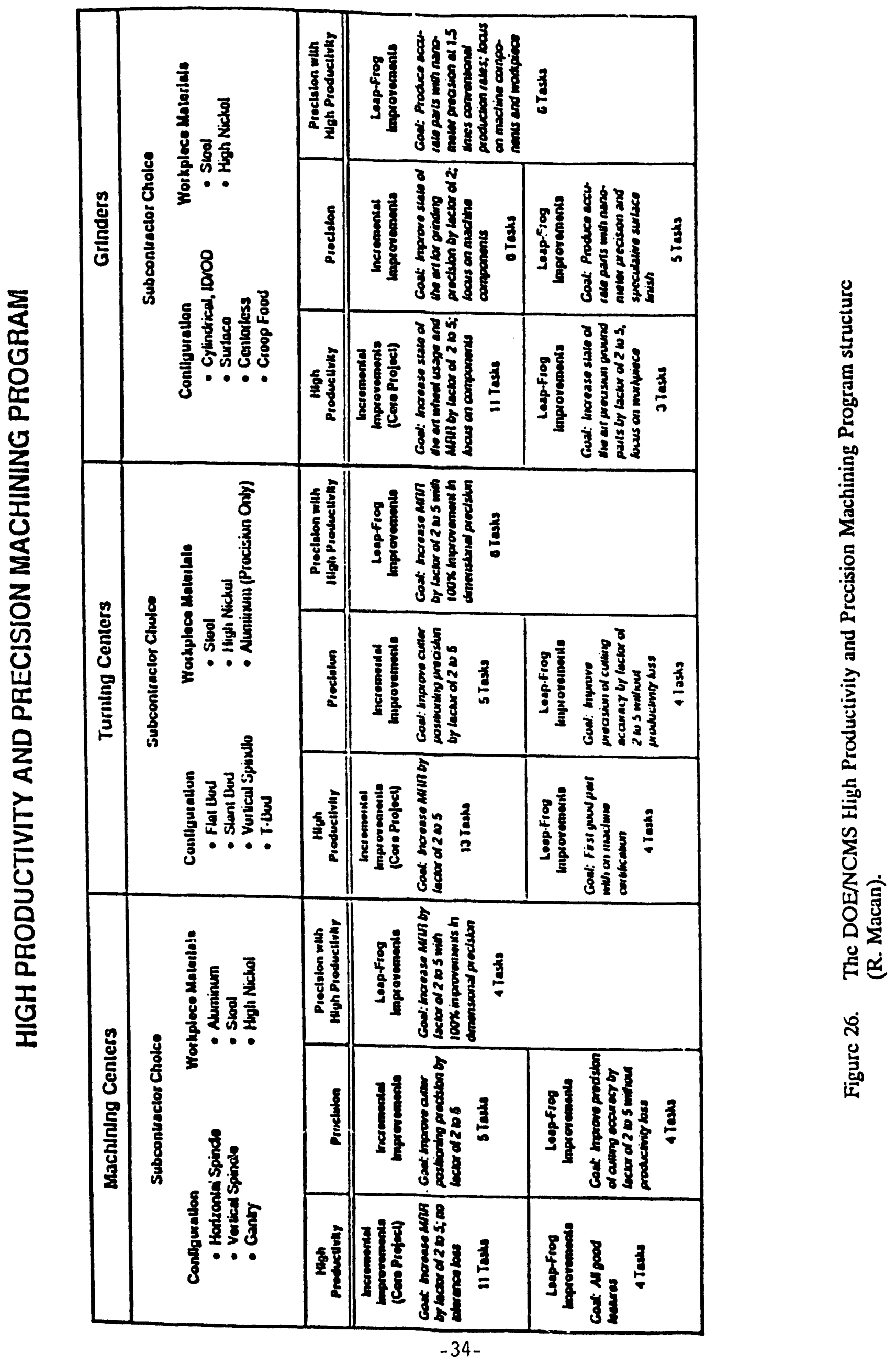




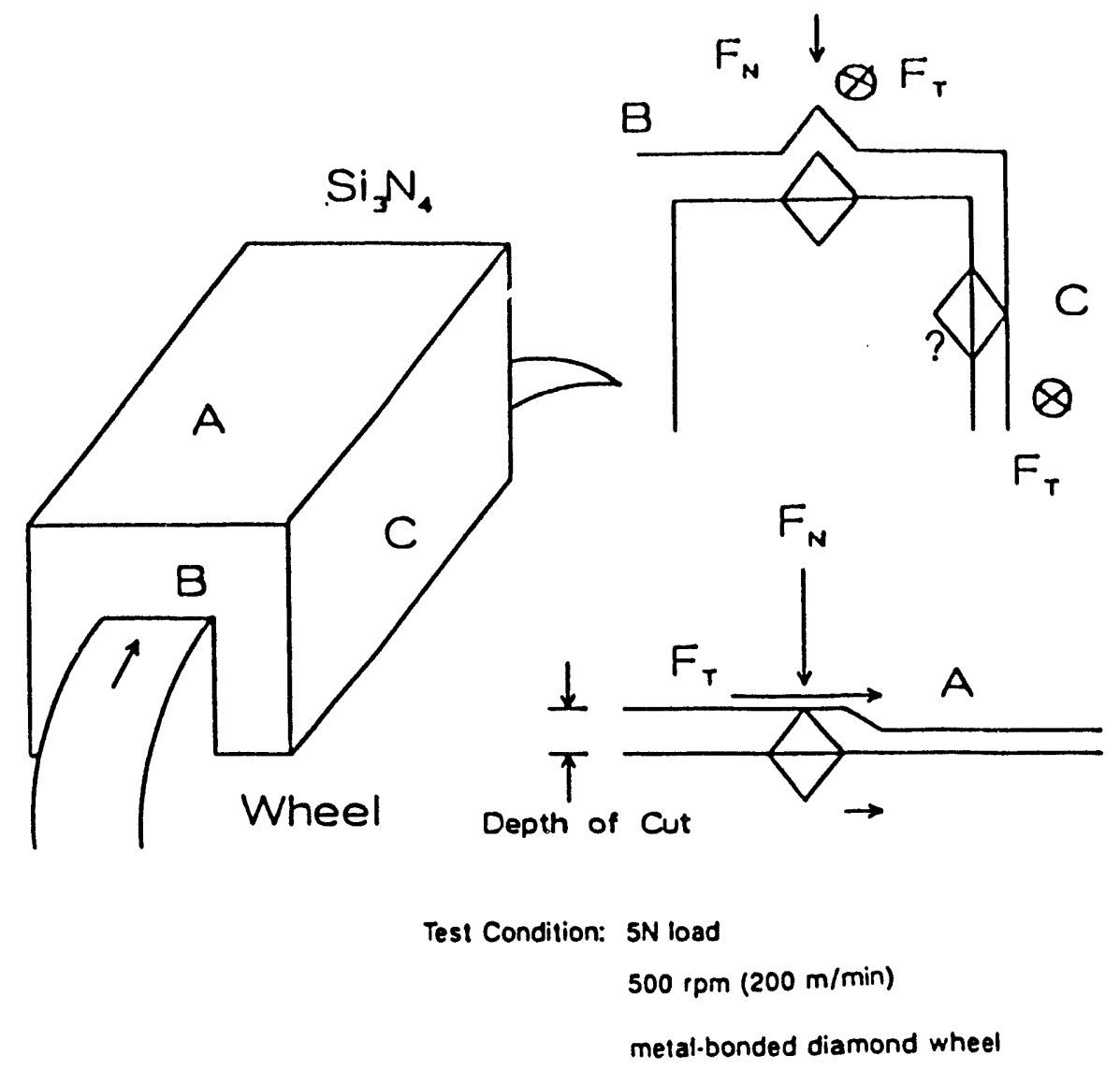

Figure 27. Diagram of geometry for chemically-assisted grinding tests on ceramics at NIST (S. Dapkunas).

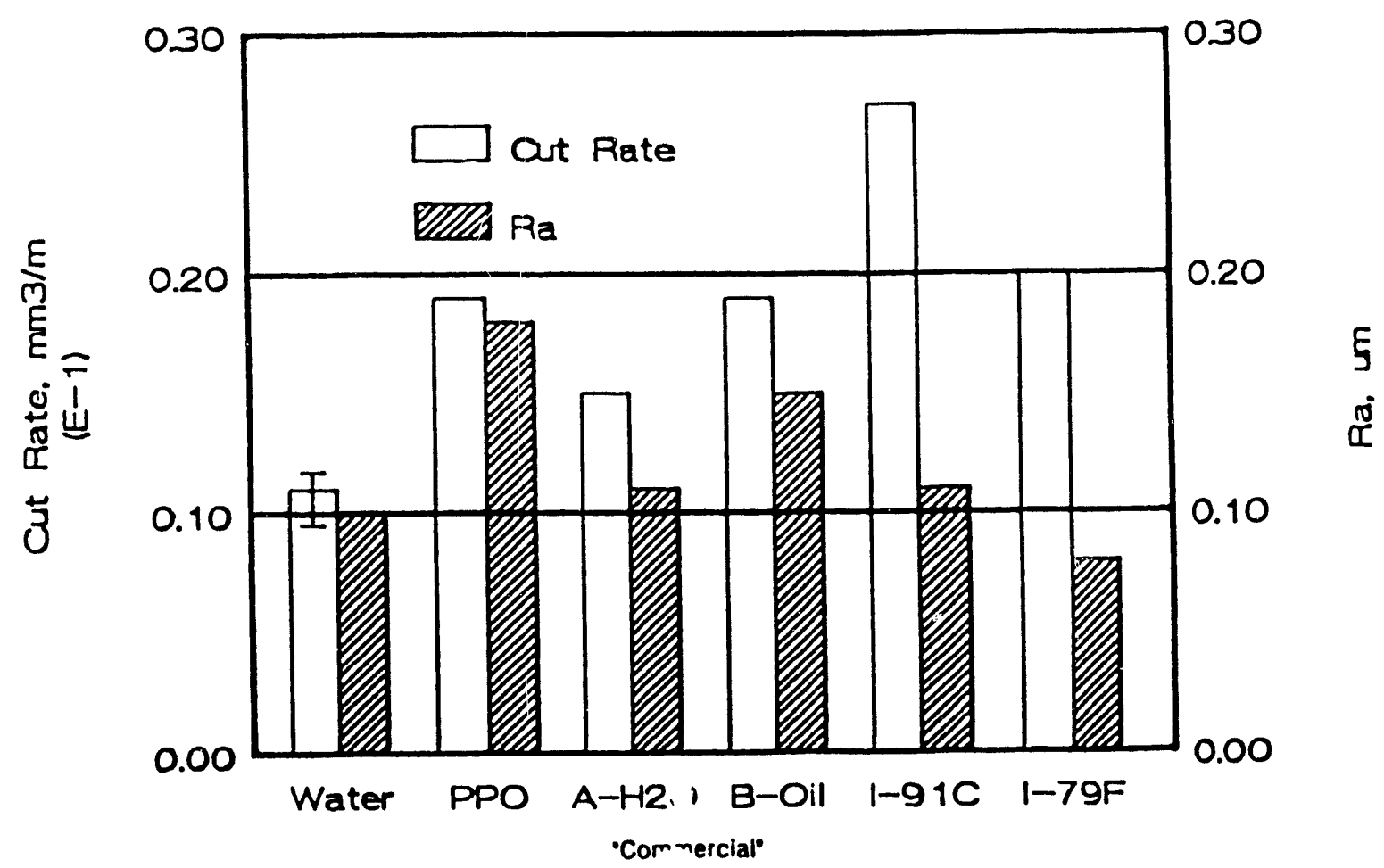

Figure 28. Preliminary data on the effects of various fluids on cutting rate of silicon nitride (S.Dapkunas). 
While not scheduled on the original program (Fig. 4), Irving Stowers, Lawrence Livermore National Laboratory, presented a brief review of precision machining work at LLNL. There is a LLNL internally-funded "Chip Science" Program which utilizes two turning machines converted to do precision grinding research. Research is underway to identify conditions for ductile, brittle, and transitional modes in grinding with special attention to the ductile grinding regime. Stowers also described the detailed, molecular dynamics models being developed for very shallow depth-of-cut orthogonal cutting situations. Some of the simulations require hundreds of hours of computing time on a Cray computer just to simulate a microsecond of cutting time in a single-phase, single-crystal material.

\subsection{THE PROPOSED CECM PROJECT PLAN}

The author presented a draft CECM project plan to the workshop attendees and invited them to complete survey forms which provided them with the opportunity to critique the plan. This survey and its results are described in Section 4.0. Since a newer, revised version of the CECM program plan evolved from the workshop and from subsequent discussions, the original May 22 plan, as presented at the workshop, will be described in summary fashion. The revised plan is described in more detail in Section 5.0.

The May 22 CECM plan is shown in Fig. 29. This plan had three main tasks and one subsidiary task: Advanced Machining Processes (AMP), Quantitative Surface Quality Criteria (QSQC), Finish/Function Relationships, and Machining Database and Technology Transfer. Figures 30 and 31 give a breakdown of the various tasks, and Fig. 32 shows the preliminary estimate of project resource allocations among the tasks.

The AMP task is the heart of the project since it involves understanding cost drivers, modeling, and improving machining processes for ceramics. The QSQC task involves finding better, production-compatible methods for quantifying the quality of machined ceramic parts. The Finish/Function task involves identifying the proper surface finishes for ceramic parts which will allow them to meet their functional requirements in the engine without creating overly rigid, cost-driving, high-tolerances. The Database task involves developing standard ways of reporting machining procedures within the project and developing a data resource for ceramic machining procedures. The information would be transmitted to $U$. S. industry through cooperative research and development agreements (CRADA's) and through publications and workshops.

Workshop attendees were provided hardcopies of the May 22 plan to aid in considering their responses to the survey forms.

\subsection{SURVEY DESCRIPTION AND RESULTS}

The CECM survey form was constructed in seven parts (Fig. 33 (a)-(d)). Part 1 provided information about the respondee so that his or her responses could be put into perspective of current job motivations and organizational responsibilities. Part 2 asked for areas of the May 22 plan which should be emphasized, de emphasized, or deleted. Part 3 had two parts, depending on whether the responder was a supplier or user of ceramic parts, and dealt with identifying the key issues in either machining cost-cutting or using ceramic parts. Part 4 asked for the responder who felt qualified to select and rank three engine parts and appropriate cost reduction targets for those parts to make viable the use of ceramics for those parts. Part 5 asked those who felt qualified to answer to rank the five machining processes which could benefit most from $R \& D$ in regard to cost reduction. 


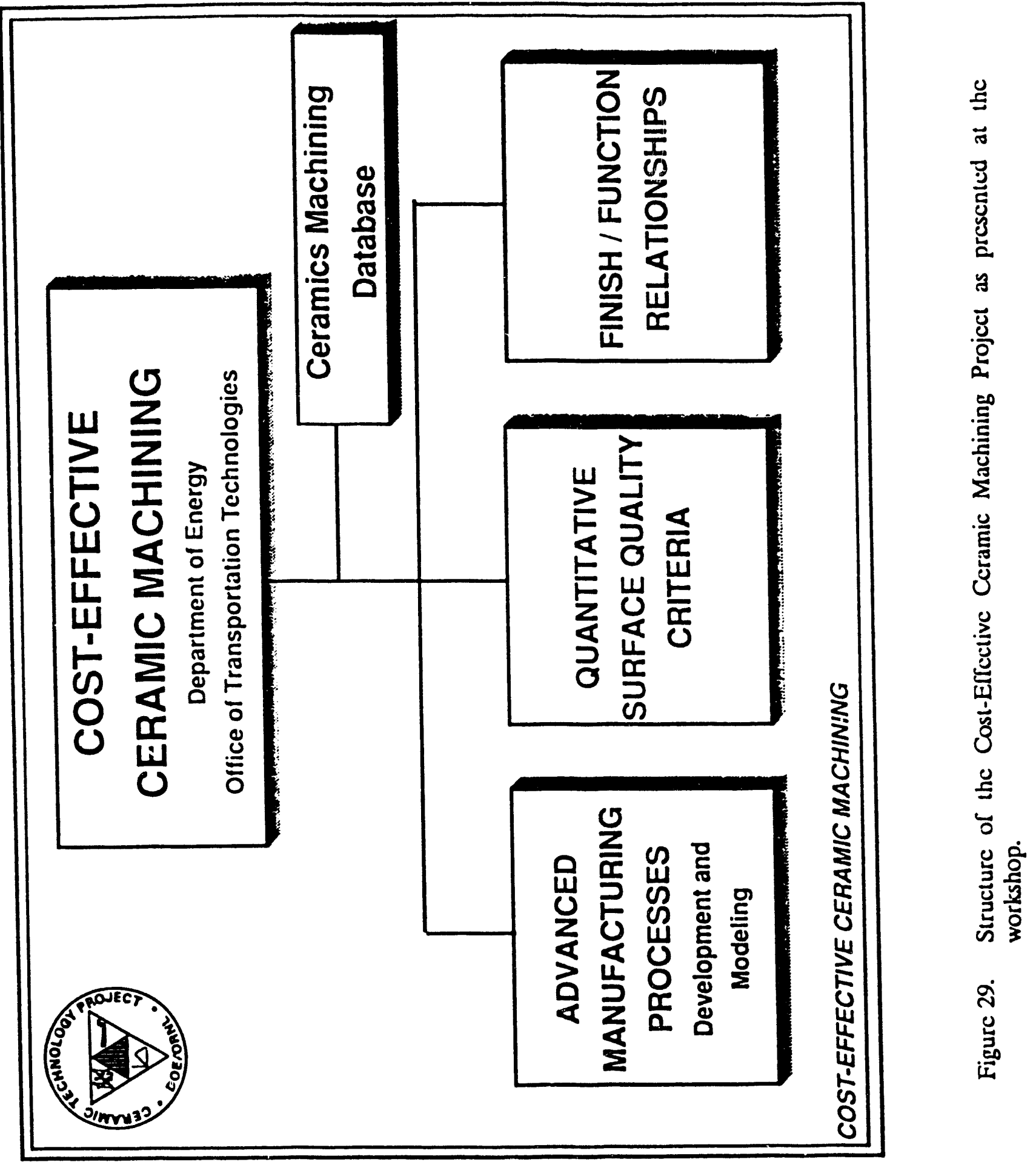




\section{ADVANCED MACHINING PROCESSES:}

Development and Modeling

1.0 GRINDIN 3 AND FINISHING PROCESS MODELS FOR CERAMICS

1.01 Mechanistic Modeling of Grinding and Finishing Processes for Selected Parts or Part Families

1.02 Development of Economic Machining Models for Ceramic Parts

1.03 In-Plant Assessments of Ceramic Machining Processes (with DP)

1.1 ADVANCED MACHINE TOOLS AND GRINDING MEDIA

1.11 Advanced Grinding Wheel Technology Development

1.12 Deyelopment of Stiff Machine Technology

\subsection{PROCESS DEVELOPMENT}

1.21 Development of High-Speed Stock Removal Methods

1.22 Arisis and Developmeni of Electro-Chemically-Assisted iMethods

1.23 Development of Novel or Non-traditional Machining Methods

1.3 INTEGRATION OF ADVANCED MACHINING METHODS AND QSQC IN PRODUCTION ENVIRONMENTS

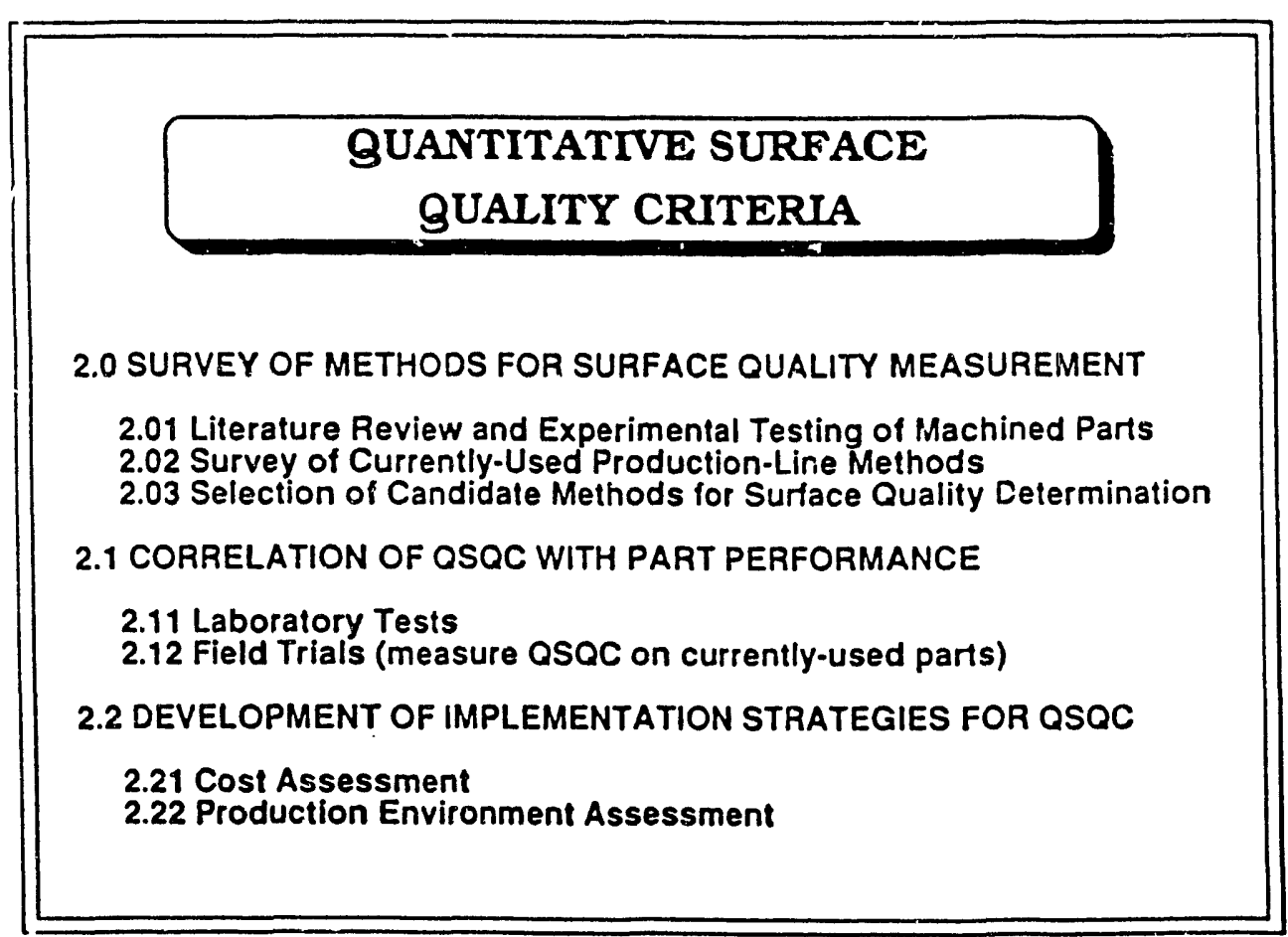

Figure 30. Topics within the subtasks on AMP and QSQC. 


\section{FINISH / FUNCTION RELATIONSHIPS}

3.0 DETERMINATION OF THE CRITICAL SURFACE PERFORMANCE REQUIREMENTS

3.01 Analysis of Requirements for Selected Parts

3.02 Selection of Laboratory Test Methods which Correlate with Service Needs

3.1 PERFORMANCE TESTING OF PARTS WITH VARIOUS SURFACE CONDITIONS

3.11 Determine which Surface Conditions Produce Satisfactory Performance using Lab Tests ( see 3.02) and in conjunction with QSQC ( see 2.11)

MACHINING DATABASE and TECHNOLOGY TRANSFER

4.0 ESTABLISH CONSISTENT METHODS FOR REPORTING MACHINING DATA WITHIN THE PROJECT

\subsection{COLLECT MACHINING DATA IN ESTABLISHED FORMATS}

4.11 Integrate Machining Parameters with OSOC Data

4.12 Include Performance Data when Available

4.13 Ensure Maximum Availability of Data to the U. S. Ceramics Industry

\subsection{CONDUCT TECHNOLOGY TRANSFER ACTIVITIES}

4.21 Workshops, Reports, and Program Reviews

4.22 Conduct Ceramics Machining Training Sessions in Conjunction with the New Precision Machining Center (DP Project)

Figure 31. Topics within the subtask on Finish/Function Relationships, and the activity on Machining Database and Technology Transfer. 


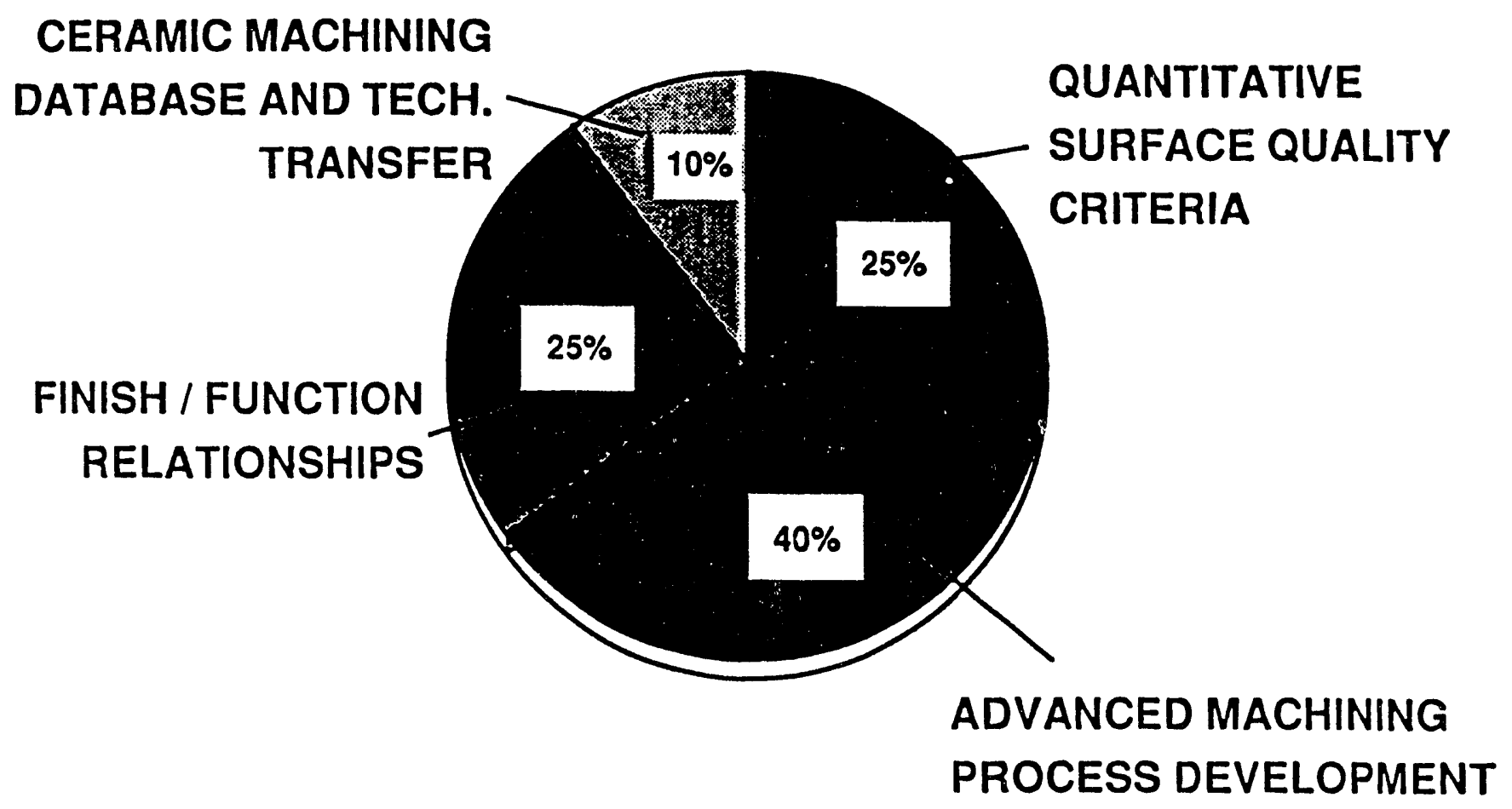

Figure 32. Estimated resource allocation based on the structure in Fig. 29. 


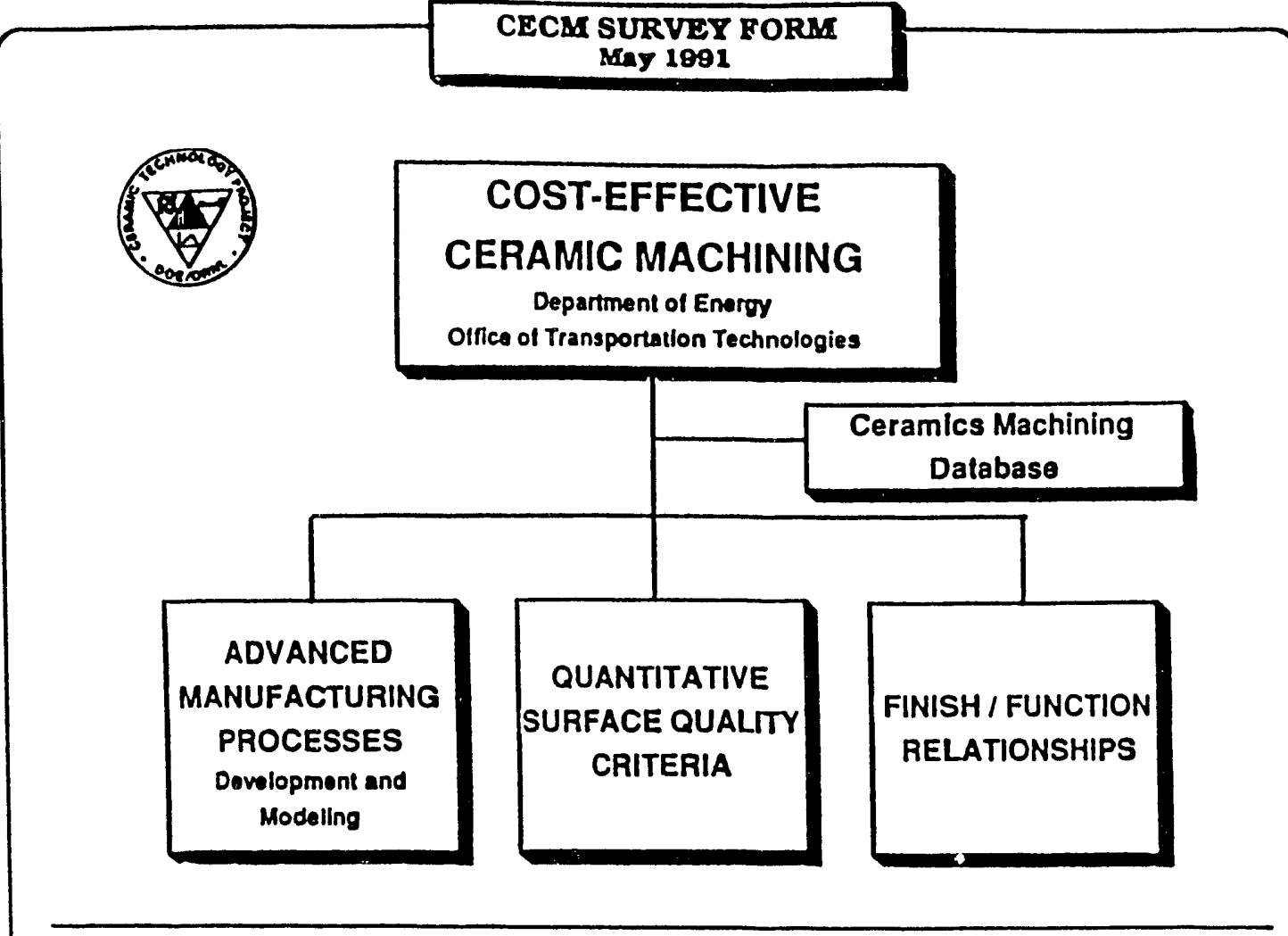

1) PROFILE

The category that best fits the orçanization I represent is:

\begin{tabular}{|ll|}
\hline ceramic material/parts producer & $\square$ non-(not-fort-profit R\&D organization \\
$\square$ machine shop & $\square$ state or local government \\
$\square$ engine / truck / automoblle manufacturer & $\square$ Industry association \\
$\square$ college of university research & $\square$ professional society \\
$\square$ U.S. Governmemt R\&D facllity (lab,etc) & $\square$ consultant \\
$\square$ U.S. Govemmemt other & $\square$ other: \\
$\square$ OEM component suppller & \\
\hline
\end{tabular}

The category that best fits my primary job responsibility is:

\begin{tabular}{|ll|}
\hline R\&D - englneer, scientist, etc & $\square$ production engineer \\
$\square$ R\&D - supervisor & $\square$ college / unlversity research \\
$\square$ private consultam & $\square$ marketing / sales \\
$\square$ program / project manager & $\square$ corporate oftlcer / execurtive \\
$\square$ machinist / machine operator & $\square$ olher: \\
$\square$ production manager & \\
\hline
\end{tabular}

Figure 33 (a). Page 1 of the workshop survey form. 


\section{2) PROPOSED PROJECT PLAN FOR CECM}

In general, the proposed DOEJORNL project plan, as presented at this workshop:

$\square$ is adequate exactly as-presented

a could be improved by considering the following changes:

Defete or de-emphasize the following parts of the proposed plan:

Include or emphasize additional technical areas (as specific as possible):

(Please use the last page if you need more space.)

3) Please answer the appropriate section below.

a) Ceramic parts suppliers or machine shops:

The information that would help me most in curting maching costs today is:

b) Users of ceramic parts:

The most important factor in encouraging my company to use ceramics is:

Figure 33 (b). Page 2 of the workshop survey form. 


\section{4) TARGET PART SELECTION}

From the list below, please circle the three parts which you think will benefit most from machining cost reduction in terms of market competition and utilization. Next to each of the three choices, estimate a reasonable cost reduction target to the nearest $5 \%$.

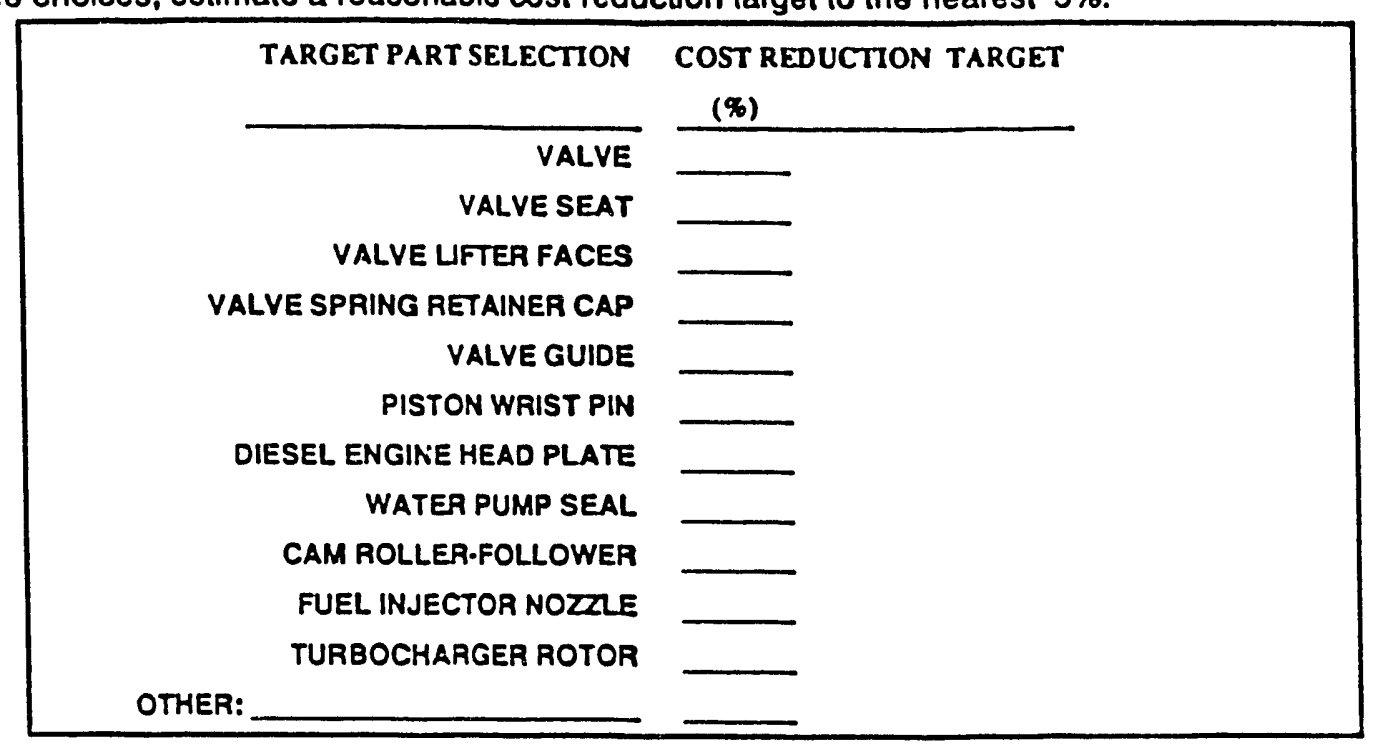

\section{5) COST DRIVERS}

Please identity and rank up 105 processes which you feel would benefit most from R\&D in cost reduction-oriented machining of ceramics for transportation system adplications.

\begin{tabular}{|c|c|}
\hline 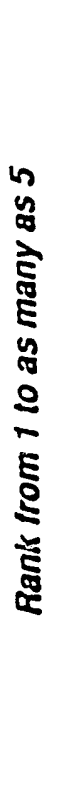 & 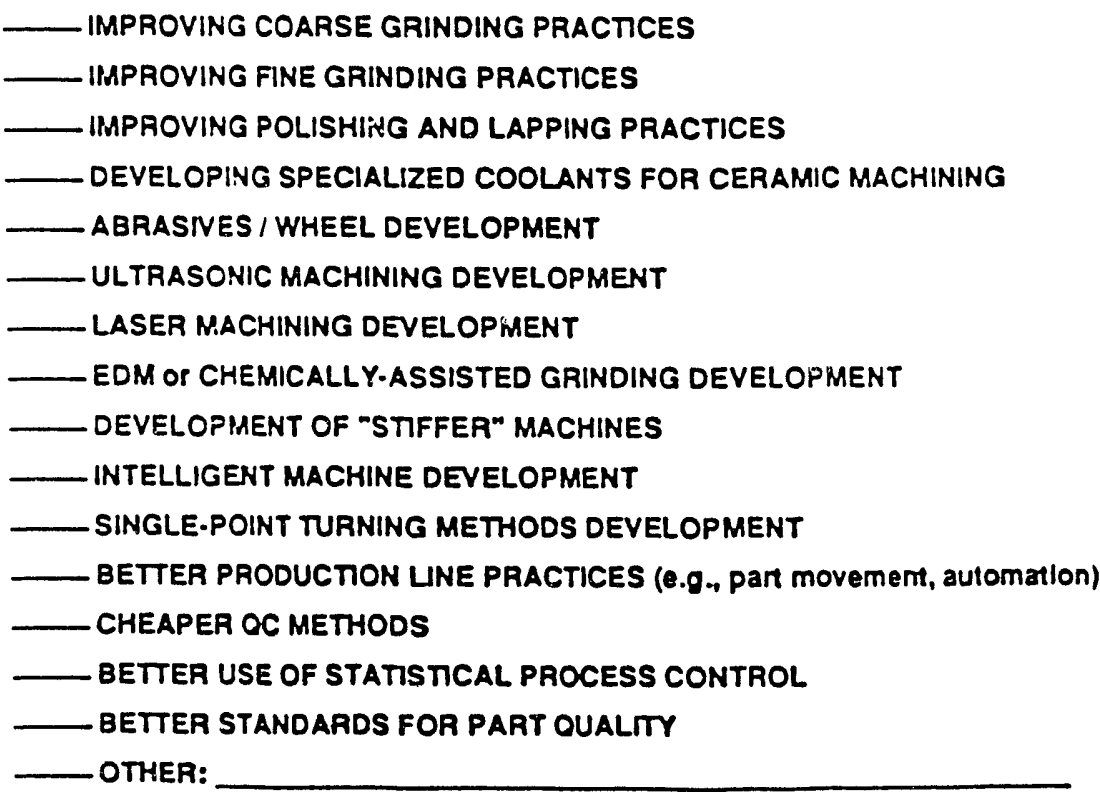 \\
\hline
\end{tabular}

Figure 33 (c). Page 3 of the workshop survey form. 
6) ADDITIONAL COMMENTS AND REMARKS ABOUT THE CECM PLAN

7) COMMENTS REGARDING THIS WORKSHOP

Do you feel your attendance at this workshop was beneficial? If so, how?

Were accomodations and ciher arrangements satifactory? Could we have done better?

Signature (Optional)

Please return this survey to the workshop organizers before leaving. Thank you for your candid remarks and for your participation in the planning process.

Figure 33 (d). Page 4 of the workshop survey form. 
Part 6 asked for general comments about the CECM project plan, and Part 7 asked for comments about the workshop organization and operation. Table 2 lists general statistics about the returned survey forms.

Part 2 of the survey asked for areas to emphasize or de-emphasize in the CECM plan. Table 3 lists these responses by affiliation of the respondee. Clearly, more individuals had areas to emphasize than to deemphasize. Two areas in particular seemed to have divergent opinions: (1) stiffer machine development, and (2) the need for academic versus part-oriented, practical approaches. Many felt that traditional machines and practices should be modified for ceramics instead of developing new, stiffer machines, but others felt that stiff machines were the key to ceramic machining. Some industrial people felt that academic approaches were not useful to them and should be kept to a bare minimum, while the university community tended to emphasize the generic, fundamental approach. However, it should be noted that a significant number of machine shop and industry people also felt a need for more fundamental research on machining. There was strong support for abrasive wheel and coolant technology as well as establishing the connection between part function and part finish. There was also a sentiment that strength testing may not be the ultimate measure of part functionality; especially, where rolling contact is involved.

Part 3a. asked ceramic parts suppliers or machine shops about the information which would most help in reducing machining costs. Their responses are summarized in Table 4. The importance of abrasive wheel selection and characterization comes through strongly in the responses to Part $3 a$. Education and guidance on machining parameters for ceramics is also seen as very important.

Part 3b. asked end-users what the most important factor was in encouraging their company to use ceramics. Table 5 lists these responses. Performance, reliability, and cost are the central themes expressed by people answering Part $3 \mathrm{~b}$.

Part 4 asked those who felt qualified to answer to select and rank candidate ceramic engine parts for cost reduction, and to select cost reduction targets for those parts. Twenty-five people answered Part 4. One might expect that the part selection would be influenced by the products of the company of the respondee; however, several trends did emerge.

Of the twenty-five first choices, valves ranked first (36\%), water pump seals were second $(12 \%)$, and the diesel engine head plate was third (8\%). Considering all parts ranked in the top five, irrespective of order, valves were again first $(60 \%)$, next were cam roller followers (48\%), turbocharger rotors (32\%), diesel engine head plate (24\%), and piston wrist pin (24\%). All other parts received less than $20 \%$ of the total vote.

The cost reduction targets suggested by the respondees varied widely, and therefore their meaningfulness is questionable. For example, target cost reductions for valvess varied between $15 \%$ and $500 \%$ [ Note: Conceptually, it is impossible to reduce the cost of a prociuct by more than $100 \%$. The respondee probably meant to reduce the cost to $1 / 5$ its present level. Such responses made computing the average value meaningless and none was computed.]. Not all people ranking components chose to select cost targets for them. Based on these responses, it is concluded that specific cost targets mist be obtained not by survey, but by one-on-one discussions with specific manufacturers and part users.

Part 5 asked respondees to rank specific machining processes which would benefit most from cost-related R\&D; thirty-five people of the forty-one returning their survey forms answered this question. As in the case of Part 4, not all respondees chose to follow directions (e.g., ranking more 
Table: 2

CECM SURVEY RESPONSES

Item

Total number of on-site attenders

Total number of survey forms returned

Number who felt qualified to answer

question 4 (part selection/cost targets)

Number who felt qualified to answer

question 5 (key process ranking)
Number

68

41

25

35 
Table 3.

\section{AREAS TO EMPHASIZE/DEEMPHASIZE IN THE CECM PLAN}

(Listed by Affiliation of the Respondee)

Areas to Emphasize

(a) Industry (including machine shop) responses:

- material research on machineable ceramics

- access only to U. S. industry -- not foreign-owned

- integrity (reliability) vs. process method

- new, high-volume processes

- near-term ('93) facilitation of product introduction

- QSQC

- validation in engines

- improve the machine-tool part of the program; stiffness is not the only problem

- design for high performance using ceramics

- contact mechanics and surface topography studies to define subsurface damage-producing conditions

- process development (1.2 of the proposed plan) is key

- standardized machining guidelines and NDE. (I believe that stiffer machines allow continuation of marginal grinding practices)

- truing and dressing

- creep feed grinding

- coolant application

- importance of fluids and (electric) fields as machining enhancements

- determine damage or enhancement properties that result from machining

- grinding wheel and new abrasive technology development

- fundamental understanding of material removal processes

- diamond-wheel technology and powder control to meet near-net shape parts

- sharing technology to assist U. S. industry

- check strength to validate each new process

- compilation, eval., and publication of currently-used mach. practices

- study of the relationship between diamond strength, bond strength, and physical properties of the workpiece

- polishing/lapping

- coolant development

- near net-shaping to grinding program linkage

- establish and publish established ceramics machining data as a base line

- need to tie machining program to one emphasizing dimensional control

- need strong ties to commercial products -- grinding research should be related to specific components rather than related to strength testing

- advanced, unproven machining concepts

- increased through-put of conventional equipment

- effect of coolant chemistry and filtration

- diamond grade/bond systems/special machine development 
- emphasize sections 1.1 and 1.2 of the plan

- high-volume machining

- wheel life/wear

- coolants

- on-line dressing

- wheel technology and coolants

- NDE and high speed inspection should be part of QSQC

- reaction layer issues and residual stress

- operator education and training

- stiffer machines

- careful definition of all components of the system

(b) University faculty responses:

- further evaluate low-energy machining

- part fixturing/sensors/control for optimum performance

- better understanding of the grinding process

- chemical-assisted grinding

- fluid mechanics of grinding wheels, e.g. high-speed flow visualization

- measurements of surface finish vs part function and as a diagnostic for machine/wheel microdynamics

- better understanding of material removal mechanisms

- expand advanced machining processes to include (a) characterization of subsurface damage, and (b) lubricants/coolants interaction with surfaces

- fear of the Japanese is irrational; spend time keeping up with them instead

- effects of grinding on performance such as rolling contact fatigue

- modeling of grinding/lapping/polishing processes to predict

microcracking - models must include temperatures

- relationships between surface properties/damage to phenomena such as rolling contact fatigue should be thoroughly investigated

- the modeling aspects should be thoroughly covered

- careful survey of the Japanese literature and build on such understanding

(c) Government and R\&D non-profit organization responses:

- performance/property/microstructure relationships

- validation of predictive models

- sensor-based control of machining

- add a task to define grinding features and performance requirements for future machines (1995-2000)

- process modeling/science as this is the area that is the weakest, and national labs have the potential to make the largest contribution

\section{Areas to De-emphasize}

(a) Industry (including machine shop) responses:

- stiff machine technology -- these already exist

- cost comparisons of metals and ceramics

- limit academic participation to 5\% 
- diamond grade/bond systems/special machine development

- emphasize sections 1.1 and 1.2 of the plan

- high-volume machining

- wheel life/wear

- coolants

- on-line dressing

- wheel technology and coolants

- NDE and high speed inspection should be part of QSQC

- reaction layer issues and residual stress

- operator education and training

- stiffer machines

- careful definition of all components of the system

(b) University faculty responses:

- further evaluate low-energy machining

- part fixturing/sensors/control for optimum perf.

- better understanding of the grinding process

- chemical-assisted grinding

- fluid mechanics of grinding wheels, e.g. high-speed flow visualization

- measurements of surface finish vs part function and as a diagnostic for machine/wheel microdynamics

- better understanding of material removal mechanisms

- expand advanced machining processes to include (a) characterization of subsurface damage, and

(b) lubricants/coolants interaction with surfaces

- fear of the Japanese is irrational; spend time keeping up with them instead

- effects of grinding on performance such as rolling contact fatigue

- modeling of grinding/lapping/polishing processes to predict microcracking - models must include temperatures

- relationships between surface properties/damage to phenomena such as rolling contact fatigue should be thoroughly investigated

- the modeling aspects should be thoroughly covered

- careful survey of the Japanese literature and build on such understanding

(c) Government and R\&D non-profit organization responses:

- performance/property/microstructure relationships

- validation of predictive models

- sensor-based control of machining

- add a task to define grinding features and performance requirements for future machines (1995-2000)

- process modeling/science as this is the area that is the weakest, and national labs have the potential to make the largest contribution

\section{Areas to De-emphasize}

(a) Industry (including machine shop) responses:

- stiff machine technology -- these already exist

- cost comparisons of metals and ceramics 
- limit academic participation to 5\%

- modeling should only be used for specific parts of a subcontract, not emphasized

- novel methods -- concentrate instead on traditional grinding and lapping

- modeling

- non-traditional machining should be limited to short-term, practical ideas

- do not emphasize new machine tools -- make existing equip. work or industry will not be able to compete

(b) University responses:

- avoid trying to optimize for specific parts - keep approach generic as far as possible

- integrate database function into other areas

(c) Government and national laboratory responses:

- stiff machine technology

- Edisonian testing without a well-stated conceptual model of what is happening. Test a hypothesis rather than testing for its own sake.

- too much emphasis on strength-testing without attempts to characterize the cause of the strength degradation such as microcracking 
Table 4.

\section{CRITICAL COST-CUTTING TECHNOLOGIES NEEDED TODAY} BY CERAMICS PARTS MAKERS AND SHOPS

Responses to Question 3a.

\footnotetext{
- a diamond wheel/data machining handbook

- wheel/cutting fluid/feed rate selection for industry

- wheel life and surface quality as a function of speeds/feeds/depth of cut/fluids

- ways to form near-net shape parts (less green machining)

- database on how to grind a range of ceramic materials

- better diamond tooling and wheels

- better means to define wheels for a given material

- grinding wheel selection with matching machining parameters for various materials

- grinding wheel development

- material removal rates and damage control

- low-cost, automated equipment for turning/milling/grinding

- CECM draft plan parts 1.1, 1.2 and 3.0, 3.1

- basic, fundamental understanding of machining practices and processes for low cost/high reliability

- leap frog technologies for high volume manufacturing

- standard MRR, coolant technology, and improved wheels

- information on performance versus surface characteristics
}

\section{Table 5.}

CRITICAL FACTORS FOR ENCOURAGING THE USE OF CERAMICS PARTS

Responses to Question 3b.

- improved performance and lower costs

- value to our customer (cost \& benefit)

- unique property which nothing else provides

- meeting reliability of engine components with '94 emissions requirements

- durability and lower component cost

- convince top management about the usefulness and superiority of ceramics through prototype demonstrations

- cost and strength testing

- increased performance by the using system, i.e., turbine,air starter, fluidic control

- reliability 
than one choice as number one, etc). Those who followed the survey directions in answering Part 5 chose abrasives and wheel development $(29 \%)$ as number one, improvements in coarse grinding (23\%) next, and improvements in fine grinding (20\%) third. In the top five answers, irrespective of ranking, were improvements in fine grinding (77\% selected this as part of their top five), abrasives/wheels (63\%), improved coarse grinding (60\%), improved polishing and lapping (43\%), new coolant development (34\%), and intelligent machines (34\%).

\subsection{SUMMARY AND REVISED CECM PLAN}

The following principal findings were obtained from the survey conducted at the CECM planining workshop:

1) Machining (grinding) of ceramic parts is a major element in their cost and likelihood of their utilization, and that the timely introduction of ceramic parts into engines is heavily dependent on driving the cost down.

2) The parts thought most likely to benefit from cost reductions through improved machining practices were valves and cam roller followers. Other highly-rated parts were turbocharger rotors, diesel engine head plates, and water pump seals.

3) The development of improved, better-specified abrasives and wheels for ceramics was felt to be very important. This will involve attention to a variety of issues such as better methods to specify grinding wheels, improving dressing practices, in situ wheel condition monitoring, improved coolants, and providing guidance to operators in the form of data compilations or handbooks.

4) Coarse and fine grinding processes were specifically targeted for focussing R\&D efforts.

5) There was a strong interest in the relationship between part performance and machining methodology.

6) Rather than advocating the development of new, stiffer grinding machines, there was a tendericy for respondees to advocate adapting or modifying existing machine tools to handle ceramics. This sentiment tends to echo U. S. industry's general reluctance to invest in updating capital equipment despite their foreign competitors' more aggressive practices in this regard.

7) There was a divergence of opinions regarding the role that modeling and fundamental machining studies should play in the CECM project. This ranged from limiting modeling and fundamental work to a maximum of $5 \%$ of the total effort to a strong advocacy for generic studies (as opposed to work on specific engine parts) with regard to material removal mechanisms and microcracking behavior in ceramics. Recommendations in this area tended to fall along organization type (universities versus industry); however, several industrial respondees also advccated a greater need for basic research on machining.

The findings of the aforementioned survey should not to be over-emphasized in developing the final CECM project plan because the population sample of industry, universities, and government was quite limited. Had a larger group or a differently composed group attended the workshop, there might have been a dihierent set of priorities expressed. Irrespective of this concern, it is clear that 
the people who completed the surveys represented a wide and divergent range of backgrounds, anc;, in this respect, it was interesting to see their common concerns.

Based on a variety of inputs from the workshop and subsequent to it, the CECM project plan has been revised. The new structure is shown in Fig. 34. Three primary tasks have been developed: (1) Advanced Machining Process Development (AMPD), (2) Ceramic Machinability and Related Performance (CMRP), and (3) Technology Transfer and Cooperative Projects (TTCP).

AMPD has the same basic objectives that the earlier plan had, but it emphasizes more of the specific issues expressed in the workshop survey. Notable among these is in emphasis on grinding wheels and abrasives and developing the methodology for using existing machine tools for ceramics. Techno-economic modeling as well as the science of ceramic machining are still present, but they may not comprise a major part of this task unless subsequent needs analyses show them to be critical to cost reduction. Demonstrations of cost-effective machining methods on selected parts has been retained in AMPD.

CMRP is a new task that emphasizes the importance of evaluating the relative machining (grinding) characteristics of ceramic materials as they are introduced or improved. It incorporates the concepts of surface quality assessment as well as how the part function as a consequence of the finished surface quality. CMRP combines the previous tasks on Quantitative Surface Quality Criteria and Finish/Function Relationships while adding the important materials issues related to evaluating a ceramic's inherent grindability. Standard test results should form the basis for an improved database on the grindability of various ceramics.

TTCP emphasizes the need to coordinate the efforts of the Transportation Technologies, CECM project with efforts, either proposed or underway, by other government agencies and industry consortia. The two primary candidates for initial cooperative projects are the DOE Defense Programs activities to establish a Precision Manufacturing and Productivity Center, and the National Institute of Standards and Technologies consortium on finish-strength relationships in ceramics. Other cooperative projects are likely during the course of the CECM project. TTCP also involves the dissemination of critical ceramic machining information to U.S. industry by various means. It is important that significant cost reduction technologies be introduced into the ceramics machining community within the next three to five years.

Future plans in the CECM project include conducting more detailed assessments of cost drivers in the ceramic machining industry, and developing a strategy for attacking the individual project tasks of the new plan in the proper sequence and with the proper priority.

\section{REFERENCES}

1. "Ceramic Technology for Advanced Heat Engines Program Plan," ORNL/TM-8896, Oak Ridge National Laboratory, June (1984).

2. "Advanced Materials Development Program, Ceramic technology Project, Addendum to the Program Plan, Cnst Effective Ceramics for Heat Engines," Oak Ridge National Laboratory, draft plan in review (1991).

3. "Advanced Materials by Design," Office of Technology Assessment, U. S. Congress, Washington, DC (1989). 

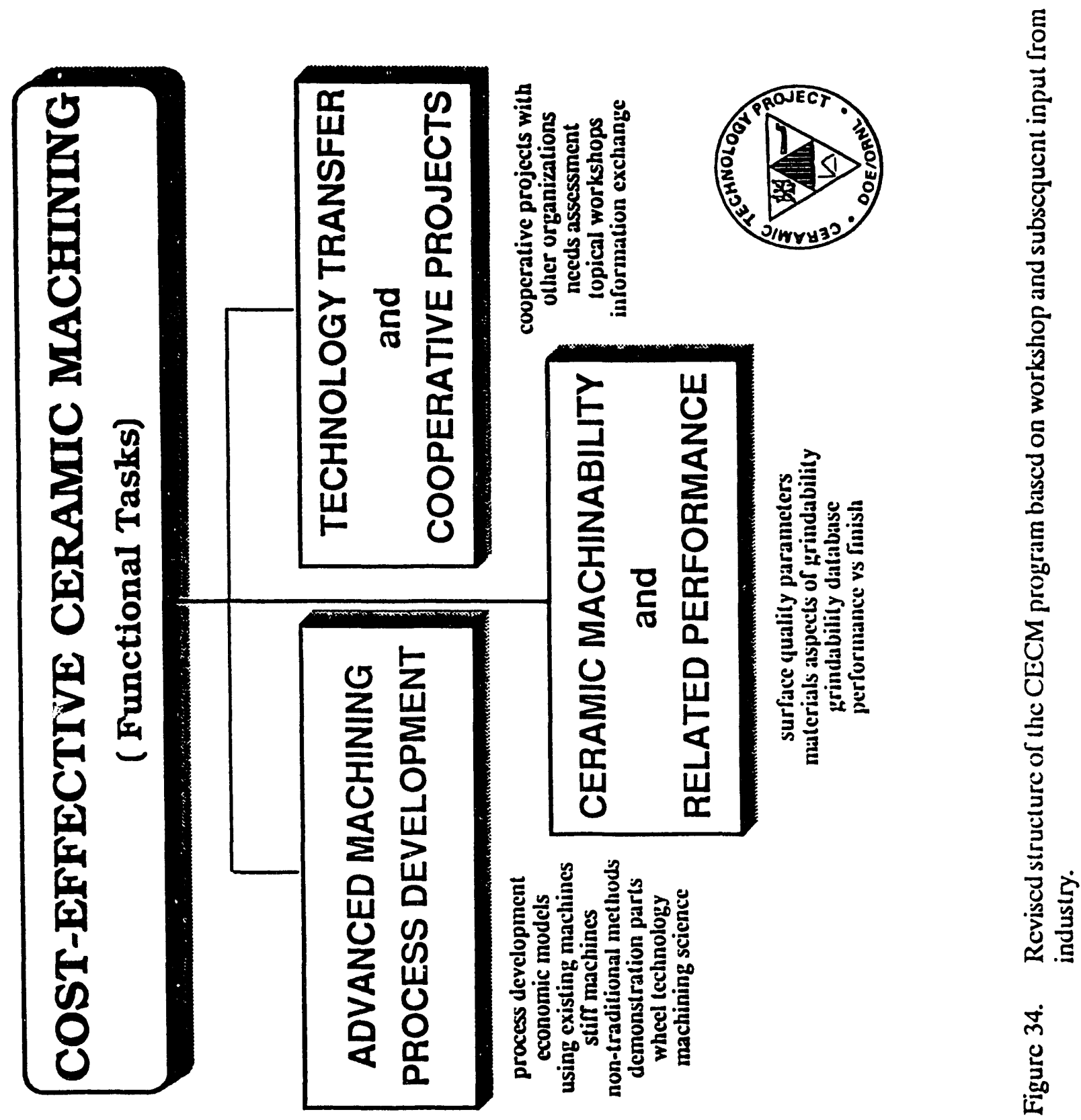
4. R. Licht, Norton Company presentation at Oak Ridge National Labortory, December (1990). Data used with permission.

5. "Bridging the Gap: An Advanced Ceramics Development and Commercialization Program," United States Advanced Ceramics Assoc.,

Washington, DC, October (1990). 


\section{APPENDIX A.}

\section{ON-SITE WORKSHOP REGISTRANTS}

The following individuals signed-in and attended the CECM Workshop on May 22-23, 1991:

Peter J. Blau

Charles J. Landry

Ronald $\mathrm{H}$. Chand

Keith P. Costello

D. Ray Johnson

B. P. Bandyopadhyay

H. J. Schock

Charles S. Yust

E. Wolff

Robert Schulz

Vivek Bhargava

Minyoung Lee

T. G. Kalamaz

George A. Fryburg

J. A. Kovach

Jim Edler

Gordon M. Reed

Alejo N. Verdes

Robert H. Licht

Louis R. McCreight

Ron Walecki

Bill Dively

Doug Dobson

S. J. Dapkunas

Susan Winslow

R. Alan Weaver

John E. Mayer

R. O. Scattergood

S. Ramanath

J. W. Picone

Carl Citron

P. St.-Pierre

S. Chandrasekar

Thomas Farris

Robert Haines

Dick Macan

J. T. M:Cabe

N. Armstrong

Wesley Lewis

Karen Weber

Ron Ellswood

Robert C. Evans

Douglas Craig

W. Keith Kahl
ORNL

Chand Kare Technical Ceramics

Chand Kare Technical Ceramics

Chand Kare Technical Ceramics

ORNL

U. of North Dakota

Michigan State U.

ORNL

Caterpillar, Inc.

DOE - HQ

GE Corporate R\&D

GE Corporate R\&D

Norton/TRW Ceramics

Norton/TRW Ceramics

Eaton, MTC

Eaton, Co RD-DC

Pratt and Whitney

Pratt and Whitney

Norton Company

NACRA

Garrett Ceramics

Corning, Inc.

Corning, Inc.

NIST

ORNL

MMES - Purchasing

Texas A\&M University

Prec. Eng. Ctr. - NCSU

Norton Company

Norton Company

CCI - Carl Citron Inc.

COMTEK

Purdue University

Purdue University

Insaco, Inc.

NCMS

MTI

Eastman Kodak

ACMC

DDC

DDC

NASA

ORNL

ORNL 
Mark H. Tysdal

Allan Thompson

Troy Washburn

Robert West

Victor Tennery

Steven Danyluk

Irving Stowers

Roger Storm

Brian Starling

Ramesh Divakar

Jyoti Chakraverty

Richard Allor

Harry Whited

Richard Chambers

Michael E. Finn

Lew Sibley

Warren C. Oliver

T. O. Morris

Bill Barkman

Hilton A. Tunnell

Phil Steger
Coors Ceramics Co.

Coors Ceramics Co.

Ridge Metals

Therm Adv. Ceramics

ORNL

U. of Illinois

Lawrence Livermore Nat. Lab.

Carborundum

Carborundum

Carborundum

Diamonite Products

Ford Motor Company

ORT Tool and Die

ORT Tool and Die

IAMS

Tribology Systems, Inc.

ORNL

MMES Y-12 Development Div.

MMES Y-12 Development Div

MMES Y-12

MMES Y-12 


\section{APPENDIX B.}

\section{COMMENTS ON THE WORKSHOP SURVEY}

An attempt has been made to faithfully reproduce comments written on the CECM workshop survey form. Slight editing was required in some cases to promote clarity. In one or two cases, it was difficult to interpret the meaning of certain wording, and the exact wording has been included for the reader's own interpretation.

1. Areas of the Draft CECM Plan to De-emphasize. (survey Question \#2)

Comments are grouped by type of organizational affiliation of the respondent.

a. Comments from Engine or Vehicle Manufacturers:

De-emphasize academia participation and modeling - only should be used in regard to specific activities within a subcontract.

b. Comments from Ceramic Companies and Parts Makers:

Capital-intensive equipment development. Possible adaptation or retrofitting of present style. I believe that a stronger, stiffer machine allows for continuation of perhaps marginal grinding processes.

De-emphasize non-traditional machining since most of the machining will have to be diamond grinding.

Do not over-emphasize new machine tools (1.12). Need to make existing equipment work or industry won't be able to compete.

c. Comments from Machine Shops, Machine Tool Suppliers, and Machining R\&D Organizations:

De-emphasize stiff machine technology since these already exist.

De-emphasize models.

d. Comments from University Faculty or Staff:

De-emphasize the optimization of processes to produce specific components from specific ceramic materials. Keep the approach generic as far as possible.

Considerable expertise on machine design-stiffness consideration is already available (e.g., Rank Pneumo).

Too much emphasis on strength testing without attempts to characterize the cause of strength degradation such as microcracks.

e. Comments from Government Laboratory Staff:

De-emphasize stiff machine development. 
De-emphasize Edisonian testing without a stated conceptual model of what is happening. Test a hypothesis rather than testing for testing's sake.

\section{f. Comments from Representatives of Industry Groups:}

Many minor (perhaps, peripheral supporting) tasks appear to have the same weight as really big major items that will need most of the time and money. Need to weight and prioritize these items.

\section{Areas of the CECM Plan to Emphasize. (Survey Question \#2)}

\section{a. Comments from Engine or Vehicle Manufacturers:}

Change wording of 4.13 to include "wholly-owned U. S. corporations", not foreignowned.

Include a line item to ensure integrity (reliability) versus process method. New high-volume processes - emphasize near-term (by 1993) facilitation of endproduct introduction.

Emphasize QSQC.

Emphasize validation in engines.

Importance of fluids and fields [electrochemical] as machining enhancements.

Determine damage/enhancement properties that result from machining activities.

Emphasize section 1.1 and 1.2.

Post-grinding or novel methods to remove grinding damage.

b. Comments from Ceramic Companies and Parts Makers:

Emphasize cost comparisons of rnetals versus ceramics.

Emphasize easily machined materials (after one sintering) and desirable properties of the material could be returned after subsequent sinter step.

Machine tool part of the plan needs improvement. Stiffness is not the only problem. The machine tool problem itself needs better definition.

There are geometric elements [of parts] unfavorable to ceramics from a reliability standpoint. It may be useful to define design rules for ceramic components for high performance and manufacturing reliability.

Contact mechanics and surface topographic studies should help to define conditions that encourage damage to the subsurface while machining.

Process development is key; however, all of section 1.0 is critical. Perhaps, more than $50 \%$ should go into this area. 
Ceramic machining guidelines and detailed NDE-QC testing.

Include data - uniform characterization of the various ceramic materials available (more than just silicon nitride).

Diamond wheel technology to increase grinding rates.

Powder control to make near-net-shape parts.

Sharing technology will assist the U.S. industry.

High-volume machining.

Wheel life and wear.

Coolants.

On-line dressing.

Polishing and lapping.

Coolant development.

Program must be closely tied into a program to enhance dimensional control and reduce stock removal.

Near-net-shaping with grinding program linkage.

Program must have strong ties with commercial products. This would require participation of end-users.

Research into grinding should be conducted on actual components rather than relying exclusively on test bars or tensile rods.

Advanced, but unproven machining concepts.

Increased through-put of conventional ceramic machining equipment.

Effect of coolant chemistry and filtration.

NDE and high-speed inspection should be part of QSQC.

Reaction layer issues should be part of part 2.0.

Residual stress should be part of $\mathbf{2 . 0}$ or $\mathbf{3 . 0}$.

c. Comments from Machine Shops, Machine Tool Suppliers, and Machining R\&D Organizations:

Establish and publish baseline machining parameters. 
Further evaluate low-energy machining.

Relationship of machining performance to mechanical and physical properties and microstructure.

Validation of predictive models.

Sensor-based control of machining processes.

Better-define grinding features and performance requirements for future machines (1995-2000).

Compilation, evaluation, and publication of currently-used machining practices.

Study the relationship between diamond strength-bond strength-and the physical properties of the workpiece material.

Diamond grit, various bond systems, special machine development for machining ceramics, or at least a modified machine.

Wheel technology.

Coolants.

d. Comments from University Faculty or Staff:

Under 1.1, need additional topics such as part fixturing, sensors, and control for optimum operation.

Under 1.22 , should be broadened to grinding process-assisted methods, includi ng electro-chemically-assisted.

The program should stress integration of the process, machine, and quality for wellcorrelated results.

A better understanding of the grinding process for ceramics is badly needed. Relationships between cost, stock removal rate, flaws induced by grinding, and strength produced must be developed.

Promote Statistical Quality Control methods.

Emphasize fluid mechanics and lubrication associated with grinding wheels. It seems that a modest effort in this area could result in a significant improvement in understanding the physical processes which occur for different grinding configurations, (e.g., high-speed flow visualization of the grinding process, etc).

Grinding and lapping of plasma-sprayed ceramic coatings.

Parts 2.1, 3.1, will require careful coordination with other efforts.

Consideration should be given to the by-products of the grinding process (i.e., health hazards, etc). 
Measurement of surface finish both in terms of functionality and as a diagnostic of the machine/wheel microdynamics.

Better understanding of material removal mechanisms and subsurface damage generation is needed. This must be done in context with machine and material parameters.

A possible novel technology: beam-assisted (laser or electron beam) heating for singlepoint turning or grinding. While more complex than adjusting coolant chemistry, it should be a more versatile technology, but chemistry should also be addressed.

Characterization/quantification of subsurface damage.

Lubricants/coolants and the interaction of lubricants with surfaces.

Fear of the Japanese is irrational. We should be spending time keeping up with the Japanese literature such as relates to the effects of grinding on performance (e.g., rolling contact fatigue), modeling of the grinding-lapping processes to predict microcracking, residual stresses, material removal. Models must include temperatures. Relationship between surface properties/damage to phenomena such as rolling contact fatigue should be thoroughly investigated.

The modeling aspects should be carefully covered.

There has been significant amount of work published in Japan and possible other countries. It is worthwhile to survey this literature carefully so that similar work is not repeated. An attempt should be made to build on such understanding.

e. Comments from Government Laboratory Staff:

Process modeling and process science as this is the area that industry is weakest in and national laboratories and universities have the potential to make the largest contribution.

f. Comments from Abrasive or Wheel Manufacturers:

Truing and dressing.

Creep-feed grinding.

Coolant application.

Grinding wheel technology development and new types of friable abrasives for grinding high-end ceramics.

Focus on fundamental understanding of material removal processes.

g. Comments from Representatives of Industry Groups:

Need to more sharply focus onto the few key areas that will make the big difference in this field: operator training, stiffer machines, careful definition of all components of the system. 
B. Comments relating to Question 3a. which asked suppliers or machine shops for the most useful cost-cutting information:

Diamond wheel data/machining handbook, for example, diamond hardness, proper wheel selection for the material being machined.

Wheel, cutting fluid, feed rate selection that would be generally accepted in industry. Wheel life and surface quality as function of speed, feed, depth of cut, fluids.

Ways to form near-net-shape parts (less green machining).

Database on how to grind a range of ceramic materials.

Better diamond tooling wheels.

Means of defining proper machining tool diamond wheel for a given ceramic material.

Grinding wheel selection matching machining parameters for various materials.

Grinding wheel development.

Material removal rates/damage control.

Low cost, automatic turning/milling/grinding equipment.

CECM Plan parts 1.1, 1.2, 3.0, and 3.1.

Basic, fundamental understanding of machine practices and processes for low cost/high reliability.

Leap-frog technologies for high-volume manufacturing.

Standard MRR rates, coolant technology, improved wheels.

Information on performance versus surface characteristics.

C. Comments relating to Question $3 \mathrm{~b}$. which asked parts users what was the most important factor in encouraging their companies to use ceramics:

Improved performance and lower costs.

Value to our customer (cost and benefit).

Unique property which nothing else provides.

Meeting the reliability of engine components with ' 94 emission requirements.

Durability and lower component cost.

Convince top management about the usefulness and superiority of ceramics through prototype demonstration.

Cost is the most important factor. Some type of material strength testing must be used. Increased performance. 
Reliability.

D. General Comments about the CECM Plan (Survey Question \#6)

Focus on engineered process machining technical ceramics is more than a skill, an art, or black magic. For technical ceramics to be truly successful and cost competitive, machining has to be an engineered science. 1st most important = define the tool (wheel), 2 nd $=$ define and control depth of cut - need to eliminate operator influence.

Better identification of surface inspection terhniques is required.

Teaming partnerships can expedite the development and introduction of ceramic components. Smaller, less formal teaming meetings might be useful. Here, very specific issues, problems, and goals could be established.

Second area: machining (grinding) of plasma-sprayed ceramic coatings. Section 2.1 \& 3.1 will require careful coordination with other efforts. Another potentially important area is analysis of the byproducts of grinding processes - health hazards, etc.

In spite of what we heard here, key elements of the problem itself must be defined as the program proceeds. Make sure that the program has enough flexibility built into it that emphasis can be changed in the future. -- Should include grinding fluid and environmental problems.

Looks good, but help to provide some more insight into the opportunities/requirements for collaboration with NIST,NACRA, NSF, etc.

Implementation will be greatly enhanced with sensor based control systems. These systems should be integrated into the applicable tasks or as a separate but parallel task.

This program falls in line with our [NCMS] activities in the grinding portion of the "High Productivity and Precision Machining Program." We have been in close contact with Fred Jones (Y-12) to pursue activities in this area.

Integrate the database into the other three programs. Also, there should be a strong basic engineering component to the program with perhaps cooperation between a number of universities and industrial/ORNL labs that would form a core of the knowledge. I imagine that industry could call upon this group to solve specific problems in machining. Consider requesting formal review and comment from NCMS to assure coordination.

Even though I understand the driving force (i.e., transportation), I believe that many other industries will not only benefit but will be more inclined to utilize advanced ceramics, even at a cost premium. To follow this practice would give greater hands-on experience to be paid for by these parts and help offset the cost-reduction requirements that the automotive/truck industries feel they need. Would it be easier to standardize and scale from a solid, good medium-size part application with all its good, real-time data?

Program effort should focus on conducting R\&D at industrial sites with lab and university assistance. Testing of results and value determination should take place at OEM's.

Also focus on cost-effective machining of components that would be used in non-heat engine applications. There is a huge market (Japan knows it) and also a need for new materials. Automotive industry has no immediate need for new materials in most cases, hence reluctance to buy into ceramics. Focus on achieving tighter tolerances - can't settle for the same tolerances as today's metal parts. 
It is important to have industry involvement in development of materials and stock removal techniques in production environment if it will be applicable to industry.

Need some type of NDE analysis method to determine the amount of damage produced on the surface from material removal methods.

When selecting target parts, it would help if there was a consideration of ceramic components used today vs. potential uses in the near term and long term. i.e., Could the parts selected reflect applications now, $2-5$ yrs, 5 yrs?

Need to make Paveto analysis of the dozens of factors influencing ceramic machining. Then focus on, say, the top 3. My guess is you would find the dominant factors that account for say, $>75 \%$ of current problems are (1) operator education in current best-practice (results are overwhelmingly operator-controlled), (2) machine stiffness - virtually no modern stiff machines (pre-WW II machines best), (3) proper selection of grinding wheel (i.e. type of diamond, concentration, and hardness. (Note: Most shop operators do not know that there are more than 1600 variants of man-made diamond tailored to specific jobs!).

Overall - excellent program. Well thought-out. Linkage to other government agencies needs to be strengthened. Linkage and prioritization of program components needs to be better defined.

We must find and concentrate on low-cost machining processes that may be used in production applications. The danger is that defense programs of DOD and DOE, such as single-point grinding, may lead us to work on the wrong technologies.

Should have provided better overview of ORNL as regards qualifications to do cost studies * .- what are your accomplishments over the past 5-10 years? The HTML demonstrates a capital investment but does not acknowledge the skills of the people in the facility. ${ }^{*} \mathrm{Ed}$. note: this comment probably refers to the cost studies described by Fred Jones of Y-12.] There should be a larger percentage of funding given to universities. The effect of residual stresses on the tensile testing should be important. This does not appear to be emphasized. Understanding this relationship would help determine the effect of residual stress on performance in practice as rolling contact.

Between 1968 and 1976, ONR sponsored a large program at SRI and some other places on strength degradation during grinding. It may be worthwhile to look at the results of that program and build on it.

Program appears very well thought-out. Need to ensure the allocation of funding by task is prioritized to give maximum support to areas with the largest potential pay-off. Need to ensure technology developed is generally available, e.g., if a new grinding wheel is developed, ensure the developer would not put a 10X premium in sales of that wheel to competitors. Am all for it and willing to help within my capabilities. Your last speaker, I. Stowers, certainly presented a very interesting set of facts. - Some government money is not going to waste. Well thought out. We should continue which cost effective processing now that reliable lab fabrication of ceramic components has been demonstrated. It looks like a good plan. It ought to help the U. S. ceramics industries. Participation of industries/universities. Labs are essential for the success of such a program in a timely manner. There seems to be much emphasis on tightly-focussed research. We as fabricators suffer from a lack of generally available fundamental knowledge that could improve our costs now (i.e.,standard MRR's) on current technology. We need some baseline numbers to start from. 
Very good WBS. I agree with approximate distribution of $40 \%, 25 \%, 25 \%, 10 \%$. There should be more clarification to diffe:entiate 2.1 from 3.1.

Should assess German, Japanese, and a few others to get the latest state of the art. We need to move quickly to improve U. S. capabilities. Use parallel approach using a few iterations over the next 5-10 years instead of sequential (e.g., analysis, modeling, etc.). Biggest gains: (a) Need for better training/education of operators and production personnel. Use video tapes, etc. (b) Get stiff, high-power machines built (new or renovated). (c) Carefully define and characterize the elements of the machining process including abrasives, binders, etc. (d) Pursue development of improved machining processes, bist not before establishing the baseline on item (c). Establish baseline before proceeding on the other WBS elements. There is a great deal of information already available from organizations like GE superabrasives. 
INTERNAL DISTRIBUTION

1. B. Barkman

2-6. P. J. Blau

7. R. A. Bradley

8. R. S. Carlsmith

9. D. . Craig

10. M. K. Ferber

11. C. L. Fitzpatrick

12. F. M. Foust

13-17. D. R. Johnson

18. F. W. Jones

19. W. K. Kahl

20. J. R. Keiser

21. W. R. Martin
22. A. C. Miller

23. T. O. Morris

24. W. C. Oliver

25. P. Steger

26. V. J. Tennery

27. H. A. Tunneli

28. R. A. Weaver

29. S. G. Winslow

30. C. S. Yust

31. Central Research office

32. Document Reference Section

33-35. Laboratory Records

36. Laboratory Records-RC

37. ORNL Patent office

EXTERNAL DISTRIBUTION

38. Scott J. Abel, Zircoa Inc., 31501 Solon Road

Solon, OH 44139

39. Richard L. Allor, Ford Motor Co, P.O. Box 2053

Dearborn, MI 48121-2053

40. Kenneth A. Anderson, Jr., Diamonite/Grace, $453 \mathrm{~W}$. McConkey St Shreve, OH 44676

41. P. R. Annese, BOMAS Mach. Spec., 334 Washington street Somerville, MA 02143

42. Neil D. Armstrong, Eastman Kodak, 901 Elm Grove Road Rochester, NY 14653-9527

43. D. B. Baird, Heat Treating Mag., 191 South Gary Ave. Carol Stream, IL 60188

44. B. P. Bandyopadhyay, U. of N. Dakota, Box 8214 Univ Sta Grand Forks, ND 58202

45. Vivex Bhargava, G.E., Corp R\&D, P.O. Box 8 Schenectady, NY 13201

46. Ed Bickford, Sandvik Coromant Co., P.O. Box 266244 Houton, TX 77207

47. James A. Branch, Ind. Cer. Tech. Inc., 37 Enterprise Drive Ann Arbor, MI 48103

48. Anthony M. Bratkovich, Jr., NMTBA, 7901 Westpark Drive McLean, VA 22102 
49. Jyoti P. Chakraverty, Diamonite/Grace, $453 \mathrm{~W}$. McConkey St Shreve, OH 44676

50. Rick Chambers, ORT Tool \& Die, 6555 S. Dixie Hwy Erie, PA 48133

51. Ronald H. Chand, Chard Kare T C, 2 Coppage Drive Worcester, MA 01603-1252

52. S. Chandrasekar, Purdue Univ., Sch. of Mech. Engr. West Lafayette, IN 47907

53. Carl citron, Sr., Carl citron Inc, Five Fir court Oakland, NJ 07436

54. William J. Coleman, Quest Integr., 2141468 th Ave South Kent, WA 98032

55. Keith P. Costello, Chard Kare T C, 2 Coppage Drive Worcester, MA 01603-1252

56. Steven Danyluk, U. of Illinois, P.O. Box $4348, M / C 246$ Chicago, IL 60680

57. Sandy Dapkunas, NIST, Matls, A-261

Gaithersburg, MD 20899

58. Brian I. Dinkha, Coors Tech Ceramics, 600 Ninth street Golden, co 80401

59. Ramesh Divakar, Carborundum Co., 1625 Buffalo Avenue Niagara Falls, NY 14302

60. Bill Dively, Corning Inc., Box 28, Rte 1 Canton, NY 13617

61. Doug Dobson, Corning Inc., Box 28, Rte 1 Canton, NY 13617

62. Peter A. Doty, DOW USA, 800 Building Midland, MI 48667

63. Dr. James J. Eberhardt, DOE - CE-34, Forrestal Bldg Washington, DC 20585

64. James Edler, Eaton Corp., P.0. Box 766 Southfield, MI 48037

65. Ronald L. Ellswood, D D Corp, $13400 \mathrm{~W}$. Outer Drive Detroit, MI 48239-4001

66. Robert C. Evans, NASA-LRC MS86-6, 21000 Brookpark Rd. Cleveland, OH 44135

67. John Fairbanks, DOE - CE-322, Forrestal Bldg Washington, DC 20585

68. Thomas N. Farris, Purdue Univ., Sch. of Mech. Engr. West Lafayette, IN 47907 
69. Michael E. Finn, I A M S, 1111 Edison Drive Cincinnati, OH 45216

70. George A. Fryburg, Norton/TRW, Salem, NH 03079

71. Clayton Guensche, Dawson Industries, 13265 E. 8 Mile Road Warren, MI 48089

72. Robert Haines, Insaco, Inc, P.0. Box 9006 Quakertown, PA 18951-9006

73. R. L. Holtman, Allison Gas Turbine, P.O. Box 420 , Code S-51 Indianapolis, IN 46206-0420

74. P. A. Janeway, Ceramic Ind. Magaz., 5900 Harper Rd, Suite 109 Solon, OH 44139

75. Thomas G. Kalamsz, Norton/TRW Cer, Salem, NH 03079

76. Elijah Kannatey-Asibu, Univ. of Mich., Dept. of Mech. Engr. Ann Arbor, MI 48109

77. Yoram Koren, Univ. of Mich., Dept. of Mech. Engr. Ann Arbor, MI 48109

78. Joseph Kovach, Eaton Corp/MTC, 32500 Chardon Rd Willoughby Hil, OH 44094

79. Dr. Edwin H. Kraft, Kyocera Indust Ceram, 5701 E. Fourth Plain B Vancouver, WA 98661

80. Dr. K. V. Kumar, General Electric Co., P.O. Box 568 Worthington, $\mathrm{OH} 43085$

81. Charles J. Landry, Chand Kare T C, 2 Coppage Drive Worcester, MA 01603-1252

82. Minyoung Lee, G.E., Corp R\&D, P.O. Box 8, KI-4B8 Schenectady, NY 13201

83. Wesley A. Lewis, Jr, A C M C, 1525 S. Buncombe Rd. Greer, SC 29651-9208

84. Robert H. Licht, Norton Company, Goddard Road Northboro, MA 01532

85. Beregszazi Louis, Defiance Mtl Pr, 1125 Precision Way Defiance, OH 43512

86. J. Richard Macan, NCMS, 900 Victors Way Ann Arbor, MI 48108

87. John E. Mayer, Jr., Texas A\&M, 117 G Thompson Hall College Sta., TX 77843-3367

88. Jack McCabe, Mech Tech Inc, 968 Albany Shaker Rd Latham, NY 12110 
89. Louis R. McCreight, NACRA, 2763 San Ramon Dr

Rancho P. Verd, CA 90274

90. Bryan McEntire, Norton/TRW Cer, Goddard Road

Northboro, MA 01532

91. Bradley J. Miller, Pakco Ind Ceram Inc, 55 Hillview Ave Latrobe, PA 15650

92. Richard T. Myzyka, ABB Autoclave Sys., 3721 Corporate Drive Columbus, $\mathrm{OH} 43231$

93. Joseph Picone, Norton Co., 1 New Bond street Worcester, MA 01606

94. Robert Pung, Diacraft Inc., 9033 General Drive Plymouth, MI 48170

95. S. Ramanath, Norton Co., 1 New Bond Street Worcester, MA 01606

96. Richard G. Rateick, Jr, Bendix Eng Controls, 717 North Bendix Dr South Bend, IN 46620

97. Stephen G. Reder, Torrington, 59 Field street Torrington, CT 06790

98. Partick D. Redington, Norton Company, 1 New Bond street Worcester, MA 01606

99. Gordon M. Reed, Pratt \& Whitney, 400 Main St, MS 114-38 East Hartford, CT 06108

100. John A. Rice, Dow Chemcial Co, 1776 Bldg Midland, MI 48674

101. James S. Roundy, Garrett Fluid Syst, P.0. Box 22200 Tempe, AZ 85284-2896

102. Ronald 0. Scattergood, N.C. State U., Box 7918 Raleigh, NC 27695-7918

103. Harold J. Schock, Mich. State U., A231 Engineering East Lansing, MI 48864-1226

104. Robert B. Schulz, Dept. of Energy, CE-34 Forrestal Bldg Washington, DC 20585

105. George Shier, Dow Chemical, 1801 Bldg Midland, MI 48674

106. Lewis B. Sibley, Tribol. Systems, 225A Plank Avenue Paoli, PA 19301

107. John W. Sperry, Dielectric Lab. Inc., P.O. Box 321 Cazenovia, NY 13035

108. Philippe D. St-Pierre, COMTEK, 235 Medick Way Worthington, OH 43085 
109. L. Brian Starling, Carborundum Co., 1625 Buffalo Avenue Niagara Falls, NY 14303

110. Roger Storm, Carborundum Co, 1625 Buffalo Avenue Niagara Falls, NY 14303

111. Irving F. Stowers, L I Nat'l Lab, P.O. Box 808, L-791 Livermore, CA 94550

112. Al Thompson, Coors Tech Cer, Oak Ridge, TN 37830

113. Scot Thompson, Allied-Sig/Aero, 7550 Lucerne Drive Middleburg Hts., OH 44130

114. Naum Tselesin, Ultim. Abras. Sys., P.O. Box 52606 Atlanta, GA 30355

115. Mark Tysdal, Coors Ceramics, 8009 th street Golden, CO 80401

116. Russell F. Upholster, Jr., Kennemetal Inc., P.O. Box 231 Latrobe, PA 15650

117. Alejo N. Verdes, Pratt \& Whitney, 400 Main st East Hartford, CT 06108

118. Ron Walecki, Garrett Ceram, 19800 Van Ness Ave Torrence, CA 90501

119. Troy N. Washburn, Ridge Metals, 121 Flint Road Oak Ridge, TN 37830

120. Karen E. Weber, D D Corp, 13400 W. Outer Drive Detroit, MI 48239-4001

121. Robert D. West, Therm Adv Ceramics, P.O. Box 220 Ithaca, NY 14851

122. T. J. Whalen, Ford (Sci Resch Lab), P.0. Box 2053, Rm S-2023 Eearborn, MI 48121-2053

123. Harry Whited, ORT Tool \& Die, 6555 S. Dixie HwY Erie, MI 48133

124. Egon Wolff, Caterpillar Inc, P.O. Box 1875 Peoria, IL 61656-1875

125. S. Charles Yoon, Cincinnati Milacron, P.0. Box 9013 Cincinnati, OH 45209

126. John A. Ziegler, Vesuvius McDanel, Box 560 Beaver Falls, PA 15010-0560

127. C. F. van Conant, Boride Products Inc., 2879 Aero Park Dr Traverse City, MI 49684

128. Office of Assistant Manager for Energy Research and Development, DOE-OR P.O. Box 2001, Oak Ridge, Tn 37831-8600

129-140. Office of Scientific and Technical Information, 175 Oak Ridge Turnpike, Oak Ridge, TN 37830. 

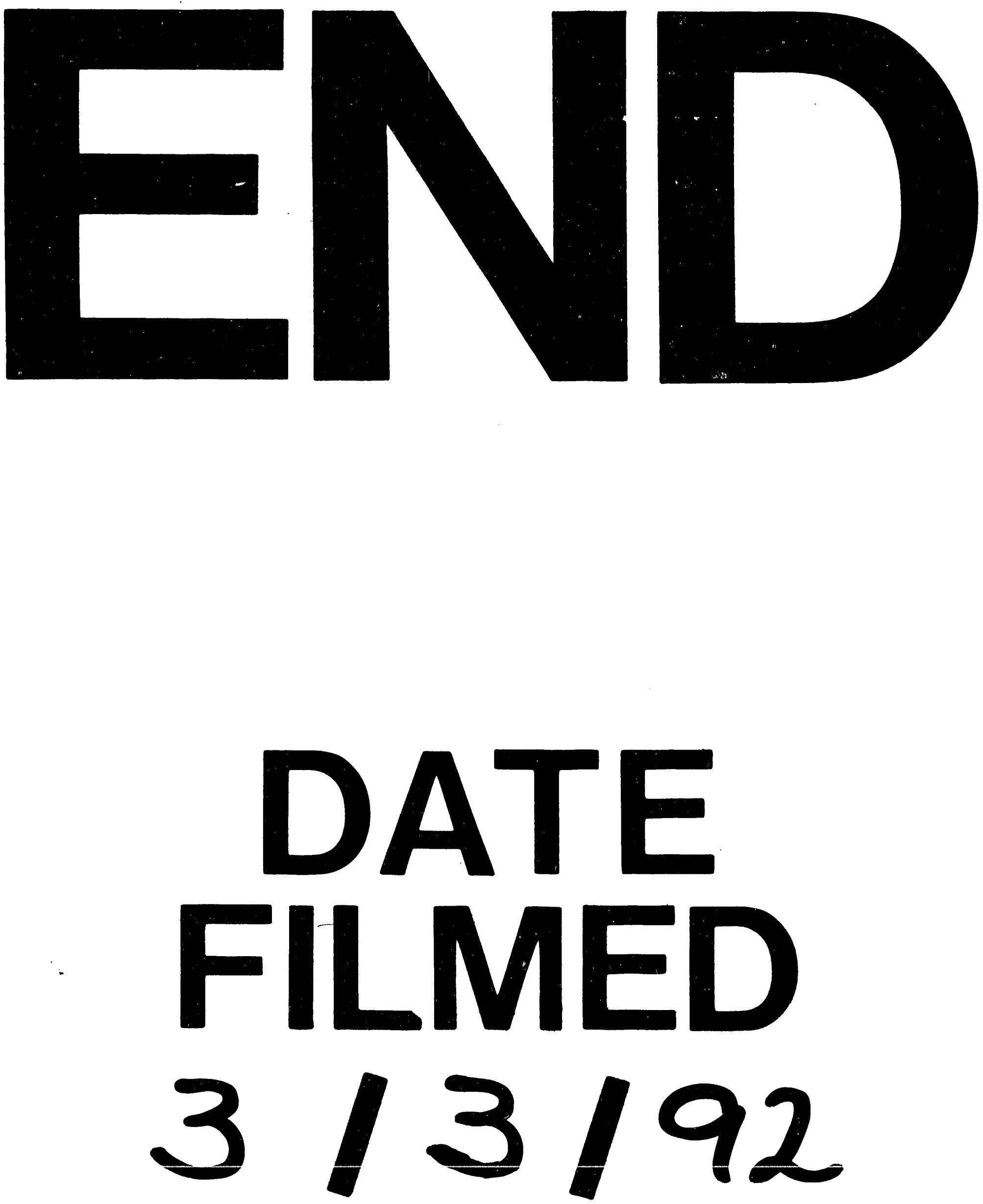
